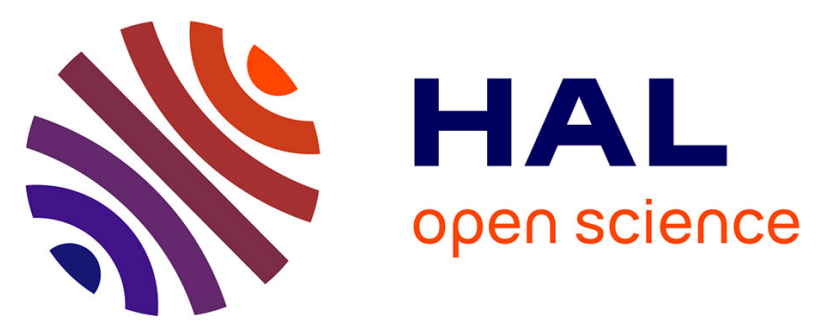

\title{
An open-source FEniCS-based framework for hyperelastic parameter estimation from noisy full-field data: Application to heterogeneous soft tissues
}

Aflah Elouneg, Danas Sutula, Jérôme Chambert, Arnaud Lejeune, Stéphane Bordas, Emmanuelle Jacquet

\section{To cite this version:}

Aflah Elouneg, Danas Sutula, Jérôme Chambert, Arnaud Lejeune, Stéphane Bordas, et al.. An open-source FEniCS-based framework for hyperelastic parameter estimation from noisy full-field data: Application to heterogeneous soft tissues. Computers \& Structures, 2021, 255, pp.106620 (26). hal03549372

\section{HAL Id: hal-03549372 \\ https://hal.science/hal-03549372}

Submitted on 31 Jan 2022

HAL is a multi-disciplinary open access archive for the deposit and dissemination of scientific research documents, whether they are published or not. The documents may come from teaching and research institutions in France or abroad, or from public or private research centers.
L'archive ouverte pluridisciplinaire HAL, est destinée au dépôt et à la diffusion de documents scientifiques de niveau recherche, publiés ou non, émanant des établissements d'enseignement et de recherche français ou étrangers, des laboratoires publics ou privés. 


\title{
An open-source FEniCS-based framework for hyperelastic parameter estimation from noisy full-field data: application to heterogeneous soft tissues
}

\author{
A. ELOUNEG ${ }^{\text {a }}$, D. SUTULA ${ }^{a}$, J. CHAMBERT ${ }^{a}$, \\ A. LEJEUNE ${ }^{a}$, S.P.A. BORDAS ${ }^{b, c, d, a, *}$, E. JACQUET ${ }^{a, *}$. \\ ${ }^{a}$ Univ. Bourgogne Franche Comté, FEMTO-ST institute, UFC/CNRS/ENSMM/UTBM, \\ Department of applied mechanics. \\ ${ }^{b}$ Institute of Computational Engineering, University of Luxembourg, Faculty of Sciences \\ Communication and Technology, Luxembourg. \\ ${ }^{c}$ Department of Medical Research, China Medical University Hospital, China Medical \\ University, Taichung, Taiwan \\ ${ }^{d}$ Department of Computer Science and Information Engineering, Asia University, Taichung, \\ Taiwan
}

\begin{abstract}
We introduce a finite-element-method-updating-based open-source framework to identify mechanical parameters of heterogeneous hyper-elastic materials from in silico generated full-field data which can be downloaded here https://github.com/aflahelouneg/inverse_identification_soft_tissue. The numerical process consists in simulating an extensometer performing in vivo uniaxial tensile experiment on a soft tissue. The reaction forces and displacement fields are respectively captured by force sensor and Digital Image Correlation techniques. By means of a forward nonlinear FEM model and an inverse solver, the model parameters are estimated through a constrained optimization function with no quadratic penalty term. As a case study, our FEMU tool has been applied on a model composed of a keloid scar surrounded by healthy skin. The results show that at least 4 parameters can be accurately identified from a uniaxial test only. The originality of this work lies in two major elements. Firstly, we develop a low-cost technique able to characterize the mechanical properties of highly heterogeneous nonlinear hyper-elastic materials. Secondly, we explore the model accuracy via a detailed study of the interplay between discretization error and the error due to measurement uncertainty. Next steps consist in identifying the real parameters and so finding the matching preferential directions of keloid scars growth.
\end{abstract}

Keywords : Finite Element Model Updating, parameter identification, in vivo, uniaxial tensile test, Digital Image Correlation, keloid, 


\section{Introduction}

From a general point of view, hyperelastic models are frequently used to model large deformations of rubber materials and biological tissues. One of the major challenges which we partially address in this paper are the choice of the, often ad hoc, hyperelastic model, and the identification of the parameters of this model.

In biomechanics, understanding diseases and injuries related to biological tissues and to treat them effectively, we need to explore how soft tissues behave under load and environmental conditions. There are two approaches to model soft tissues: bottom-up and top-down.

In bottom-up approaches, the complexity of the tissue is accounted for explicitly by accounting for tissue substructures, meso/micro/nano and molecular structures.

In top-down approaches, the complexity is built through phenomenological constitutive laws which make a mechanistic account of the complexities and intricacy of the subscales. Whilst the former enable a thorough description of the interplay between various physiological and external mechanisms, they are complex to build and require advanced microscopy and imaging techniques, which are not readily available in clinical environments. The latter, on the contrary filter unnecessary information (which depends on the main objective of the models) whilst retaining the features of the model which have a significant impact on the behaviour of the system. To describe subscale behaviour within a single "homogenised" framework, these top-down constitutive models must resort to material parameters in which the subscales are lumped.

Once a suitable constitutive model is identified, for instance using Bayesian model selection [1-3], the identification of the parameters with limited information becomes the principal difficulty. To do so, one of the main techniques consists in performing a multi-parameter optimisation where the solution of the problem using a numerical model is compared to experimental results, thereby enabling the "update" of the parameters. This is known as Finite Element Updating (FEMU).

Once the probability distributions for the constitutive parameters have been identified, along with their confidence intervals [4, 5], the following task, which we do not address here, is to propagate the uncertainty in those parameters, so as to measure their importance on the quantities of interest to the clinician. The interested reader is referred to [6] for stochastic methods focusing on the propagation of uncertainties through partial differential equations associated with finite elasticity, in particular on target motion and acceleration methods [7].

These ideas have been pushed forward with the goal of discriminating between discretization error and model error in a series of papers [8-10], where real-time error estimation method for surgical simulation and guidance are described in detail [11].

A trend in biomechanics is the development of real-time modelling and simulation methods [12,13] as well as virtual and augmented reality engines for surgery [14-16]. The algorithms put forward are able to identify and update, on the fly, the model parameters associated with soft tissues.

During the last few decades, more traditional methods have been devised to estimate the parameters of solid materials in general, without requiring real-time simulations. To this end, inverse methods based on combining full-field measurements and the finite element method (FEM) have been frequently used [17,-19]. The whole inverse problem process is then known as "finite element method updating" 
(FEMU). The earliest implementation of FEMU was possibly performed in 1971 by Kavanagh and Clough [20], where they tackled the problem of identifying mechanical properties in elastic solids.

The FEMU method is an iterative process whereby physical FE model parameters would be updated continuously until the discrepancy between the simulated and measured displacements and forces is minimized (in a certain norm). The major advantage of this approach is the identification of every possible mechanical parameter in regions that are difficult to access; or unstable medium where the uncertainty is high, especially for materials undergoing large deformations. To acquire full-field measurements, different optical techniques, including digital image correlation (DIC) are commonly used [19, 21]. The procedure has been integrated into FEMU frameworks in many mechanical characterization studies; in linear elasticity [22-24], in elasto-plasticity [25-28], in viscoelasticity [29] and in hyperelasticity [30-32].

One type of model which is able to describe the complexity of soft tissue deformation is known as hyperelastic material models [33,34]. Those models have been used in conjunction with FEMU inverse approaches using full-field imaging techniques [35]. In this way, mechanical parameters can be identified for a number of biological materials: skin [36- 38], arteries [39,40], lung [41, 42] and others [43-45].

To simulate the hyperelastic behavior of soft tissues, numerous phenomenological constitutive models have been developed [35, 46, 49].

Hyperelastic models may be isotropic or anisotropic. They are characterized by a strain energy density function, where polynomial, exponential and logarithmic terms are combined [50]. Neo-Hookean [51], Mooney-Rivlin [52], Ogden [53] and Yeoh model [54] are possible treatments of large strain elasticity which are particularly often used in biomechanics. A simple hyperelastic constitutive law was proposed in 1996 by Gent et al. [55] for rubber. Gent's model has also been used to identify the material parameters of arterial walls [56] and porcine brain tissues [57,58]. Its strain energy function involves a logarithm of the first invariant of the Cauchy-Green strain tensor. It consists of only two parameters $\mu$ and $J_{m}$ corresponding, respectively, to the shear modulus and a parameter related to the limited extensibility of macromolecular chains. Hyperelastic, or rubber-like, materials are constituted by a network of those long flexible randomly oriented chains [59].This limitation is lately considered in skin and heart tissue characterization [60,61], the two most analyzed biological tissue kinds. Horgan and Saccomandi have associated molecular-statistical properties to the two parameters of Gent model [56].

The main goal of this paper is to validate a numerical pipeline based on an open-source, open-data, open-protocol framework to identify the hyperelastic parameters of a heterogeneous soft tissue. The inverse identification is performed using a FEMU approach. The data are fabricated from a nonlinear FE model simulating in situ and in vivo extension test. The full-field displacement measurements are obtained with DIC, while the reaction forces are measured by a force sensor. The two data sets are used to optimize the constrained objective function with no quadratic penalty function.

As a case study, we simulate the in vivo uniaxial test performed with a light extensometer on a bi-material media. The model consists of an heterogeneity (keloid) surrounded by healthy skin, as described in the following studies: Jacquet et al. [62] and Chambert et al. [63]. Keloids are benign tumours growing continuously and progressively over the human skin surface [64]. The evolution of keloids is known to be related to many factors, biological, genetic and biomechanical [63,65]. Beside the psychosocial effects caused by the unpleasant keloidic shapes, such as anxiety and depression, keloid tumours tend to limit the motion of surrounding skin because they are stiffer and more isotropic. Moreover, they create local stress and strain concentration at the interface between the tumour (also known as scar) and 
the skin, which are believed to be correlated with the subsequent growth and evolution of the keloid. Understanding the mechanical behaviour of keloids and its interaction with surrounding tissue is of importance to better predict and contain their growth [66-68].

Note that Bayesian inverse approaches provide another regularisation approach. As the inverse problem is ill-posed, stochastic approaches "fuzzify" the values of the parameters which are no longer deterministic. This makes the identification process more flexible, as the parameters are no longer constrained to take one and only one value but become probability distributions, whose moments need to be identified. Bayesian approaches are particular stochastic methods which rely on prior expert knowledge to regularise the inverse problem by constraining the search space. The interested reader is referred to [4].

As a first step, we introduce the data acquisition process of the simulated test. Then, we provide details on the process scheme of our FEMU framework implemented in FENICS [69], as well as its internal building blocks, such as the forward FEM and the inverse solvers. A 2-D mesh convergence study is done in terms of element size and interpolation degree to determine a reference mesh, assumed to be the most accurate so far. By generating dummy data on the reference mesh with fixed Gent parameters into both materials, we apply the inverse identification on other coarser meshes. This procedure helps to define a low-cost mesh and to analyze the sensitivity of the model as function of discretization errors [70]. Moreover, we perform a sensitivity analysis as function of dummy measurement noise [71]. First, we vary the noise levels on the input data (displacement fields and reaction forces). Then, we vary the amount of the DIC frames used to minimize the cost. As result, we explore the limits of the numerical model. In other words, we define the maximum deviation of the measurements that make them exploitable with a view to identifying accurately the material parameters.

The complete FEnICS implementation, the meshes and all associated dummy data are available: https:

//github.com/aflahelouneg/inverse_identification_soft_tissue.

\section{Methodology}

\subsection{Data acquisition process}

The numerical process developed in order to identify bi-material soft tissue parameters is based on a Finite Element Method Updating inverse problem, where we simulate the in vivo uniaxial tensile test performed on human skin. Our focus is on a butterfly-shaped keloid scar situated on the left upper arm of a Caucasian skin presented by Chambert et al. [63]. From that uniaxial test (Fig. 11, two sets of mechanical information are gathered simultaneously for each load step: reaction force, using the force sensor, and displacement field, from Digital Image Correlation (DIC), as described by Jacquet et al. [62].

We use this load-displacement data to optimize a constrained objective function, where the discrepancy between the observed and the simulated mechanical response of keloid/healthy-skin during the load is minimized. From an arbitrary choice of material parameters, we create numerical data, which we artificially pollute by random noise. This procedure enables us to validate the parameter identification process and to analyse the uncertainties related to the whole model.

\subsection{Implementation framework}

The strategy used in this paper to identify the biomechanical parameters is optimizing a specific cost function such that the discrepancy between the experimental data taken as reference and the model 

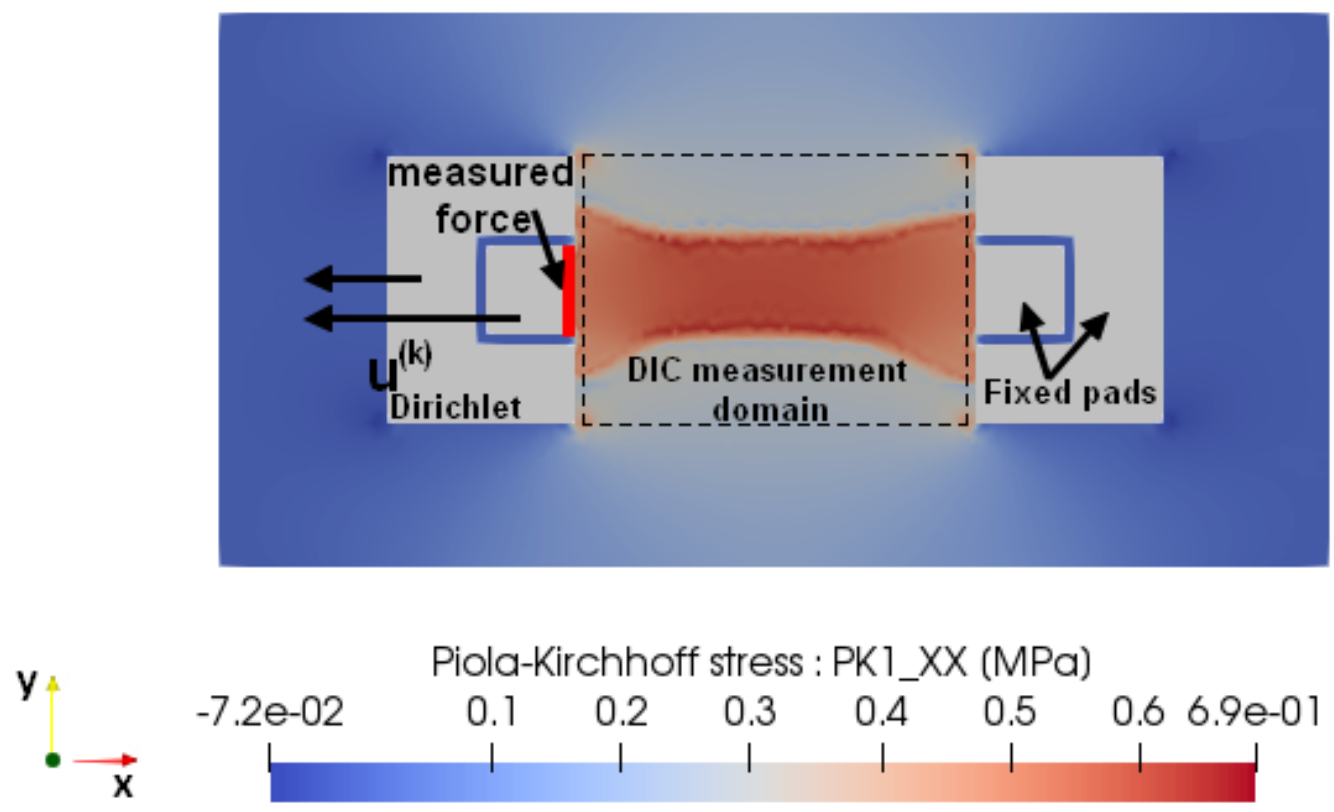

Figure 1: Output data of keloid-skin undergoing large deformation in an uniaxial test secured by an Ultra-light extensometer [62]. The reaction force is measured on the intern pad surface $\Gamma_{\text {Lpad }}$ in contact with the keloid (red line) and the displacement field is captured with a camera within a fixed frame (dashed lines).

solution is minimised, by means of a Newton-Gauss method.

Within FENICS development environment, we have entirely implemented a finite element model update (FEMU) framework [20,72,73], consisting in a collection of open-source components with ability to enable automated solution of PDEs [69]. The first step is to set an initial guess of material parameters $\boldsymbol{\theta}^{(0)}$, followed by the determination of displacement fields on a chosen zone of interest and reaction force on the left pad. Then, by comparing the model with imported data, the objective function is evaluated and a new set of parameters is computed. The process is repeated again until the variation of all parameters reach a value below the threshold.

For biomechanics, there are two major advantages to using FEnICS. The first is the ease with which constitutive relations can be added, within a single line of code. The second is the ability of FEnICS to automatically and symbolically differentiate any expression, thereby leading to automatic sensitivity analyses [74].

For details, the interested reader is referred to the recent papers of [6,7, 75], where the framework is described in detail for particular cases in biomechanics and the code is provided online here. http: //bitbucket.org/unilucompmech/stochastic-hyperelasticity The FEMU inverse method has been used successfully in recent publications [31,76,77]. The flowchart of the method is shown in Figure 2

\subsection{Forward FEM solver}

In this part, we focus on the structure of the numerical simulation that takes as input the keloid geometry, the boundary conditions and the constitutive model, and gives as output the displacement field and the 


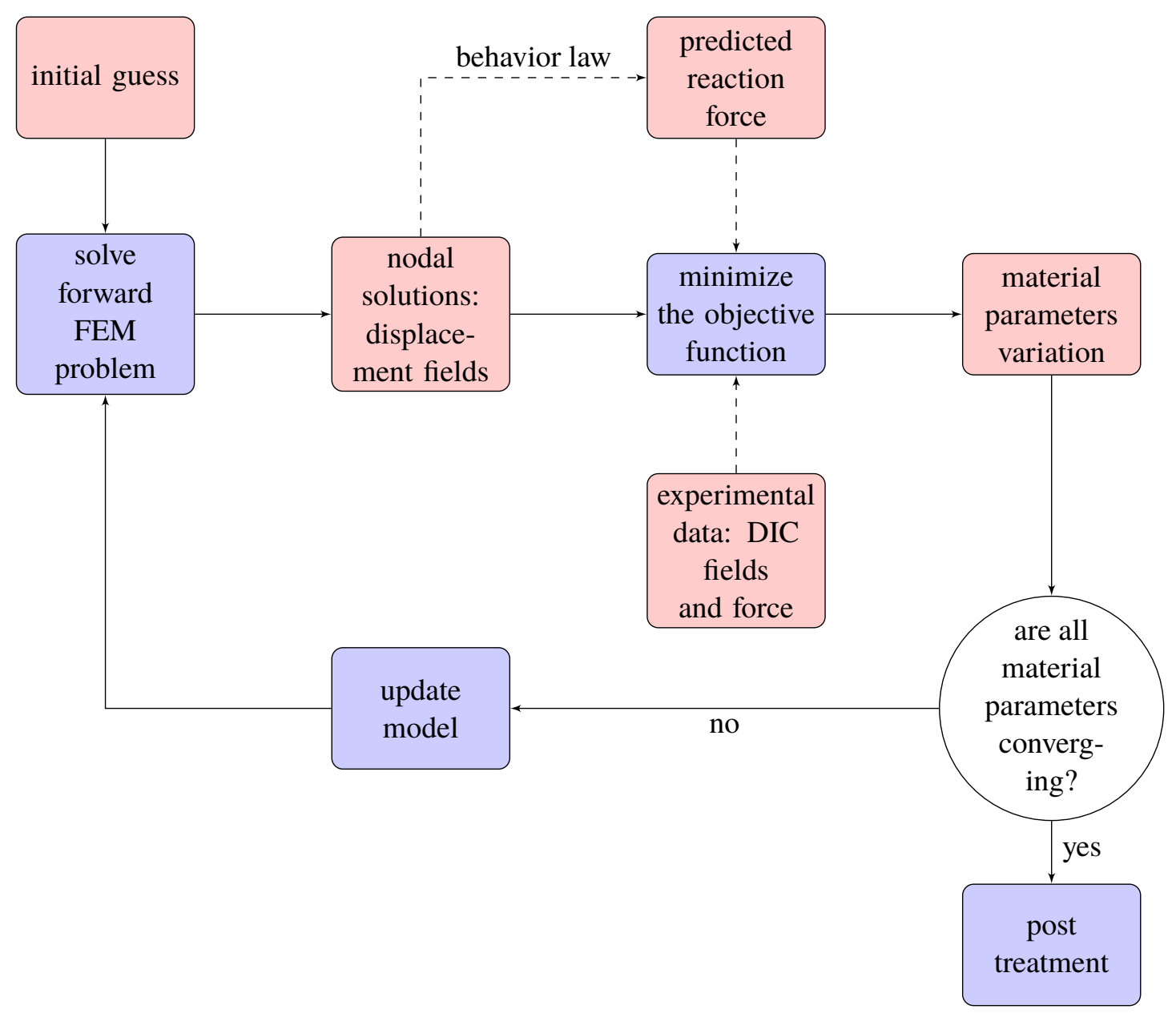

Figure 2: FEMU-based inverse identification process scheme

reaction force on the pad, derived from the latter. We assume that:

- Plane strain conditions are made for skin and keloid structures considering that the inner layer of skin is attached to muscles and subcutaneous tissues.

- The keloid scar and healthy skin are both modelled as isotropic homogeneous soft tissues and respond to the same hyperelastic behavior law, but with different sets of parameters.

- There are no body force and no traction forces applied on external boundary conditions.

- Nonlinear quasi-static analyses are carried out.

\subsubsection{Variational formulation}

The numerical model domain is divided into three sub-domains $\Omega=\left\{\Omega_{1} \cup \Omega_{2} \cup \Omega_{3}\right\} \subset \mathbb{R}^{2}$ (Fig. 3). Experimental process is controlled by a prescribed displacement $\bar{u}(t)$ during a time $t \in[0, T]$ such as $\bar{u}(0)=0$ and $\bar{u}(T)=\bar{u}^{\max }$. Hence, at any time, the imposed boundary conditions on the pads are all of Dirichlet type on boundary $\Gamma_{\text {Lpad }}($ Fig. 1).

Considering rate-independent material and quasi-static hypothesis, at any time $t^{*}$, given an admissible displacement field such as $\boldsymbol{u}=\bar{u}\left(t^{*}\right)$ on $\Gamma_{\text {Lpad }}$ and $\boldsymbol{u}=0$ on $\Gamma_{\text {Rpad }}$, total potential energy is expressed as 


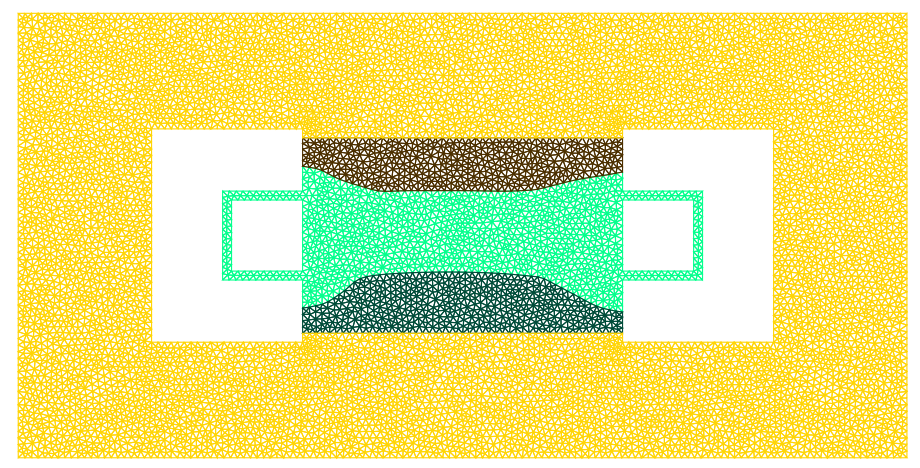

Figure 3: The geometrical model of the uniaxial test on a bimaterial soft tissue consisting in 3 subdomains: $\left(\Omega_{1}\right)$ keloid scar media (green), $\left(\Omega_{2}\right)$ peripheral healthy skin media (dark) and $\left(\Omega_{3}\right)$ outbound healthy skin zone (yellow). The outside boundaries are free to move (no displacement constraint).

$$
\Pi(\boldsymbol{u})=\int_{\Omega_{1} \cup \Omega_{2}} \psi_{\mathrm{hs}}(\boldsymbol{u}) d v+\int_{\Omega_{3}} \psi_{\mathrm{k}}(\boldsymbol{u}) d v-\int_{\Omega} \boldsymbol{b} \cdot \boldsymbol{u} d v-\int_{\partial \Omega} \boldsymbol{t} \cdot \boldsymbol{u} d s
$$

where the body (respectively surface) forces, $\boldsymbol{b}$ (respectively $\boldsymbol{t}$ ) vanish because of the absence of external forceswhere the body and the surface forces $\boldsymbol{b}$ and $\boldsymbol{t}$ vanish because of the absence of body force and the displacement (Dirichlet) boundary conditions. [R2]

$\psi_{\mathrm{hs}}$, respectively $\psi_{\mathrm{k}}$, is the elastic strain energy density that characterizes the mechanical behavior of the hyperelastic material related to healthy skin, respectively keloid.

One could show that mechanical equilibrium is equivalent to minimization of total potential energy [69.78]. Let's denote $V(\Omega)$ the space of admissible displacement such as $\boldsymbol{u}=\bar{u}\left(t^{*}\right)$ on $\Gamma_{\text {Lpad }}$ and $\boldsymbol{u}=0$ on $\Gamma_{\text {Rpad }}$ and $V_{0}(\Omega)$ the space of admissible variations $v$ such as $v=0$ on $\Gamma_{L p a d} \cup \Gamma_{\text {Rpad. }}$. Hence at any time $t^{*}$, for all admissible variations $v \in V_{0}(\Omega)$, forward problem consists in finding the displacement field $\boldsymbol{u} \in V(\Omega)$ solution of 1

$$
L(\boldsymbol{u} ; \boldsymbol{v})=\mathbf{0}
$$

where $L$ is the variational equation of the quasi-static equilibrium (the directional derivative of $\Pi$ with respect to change in $\boldsymbol{u}$ ) (Algorithm 1 and https://fenicsproject.org/docs/dolfin/2017.2.0/ python/programmers-reference/fem/solving/NonlinearVariationalProblem.html).

$$
\left.L(\boldsymbol{u} ; \boldsymbol{v}) \approx \frac{\Pi(\boldsymbol{u}+\epsilon \boldsymbol{v})}{\epsilon}\right|_{\epsilon \rightarrow 0} .
$$

${ }^{1}$ for details, please refer to Hauseux et al. [6]. 


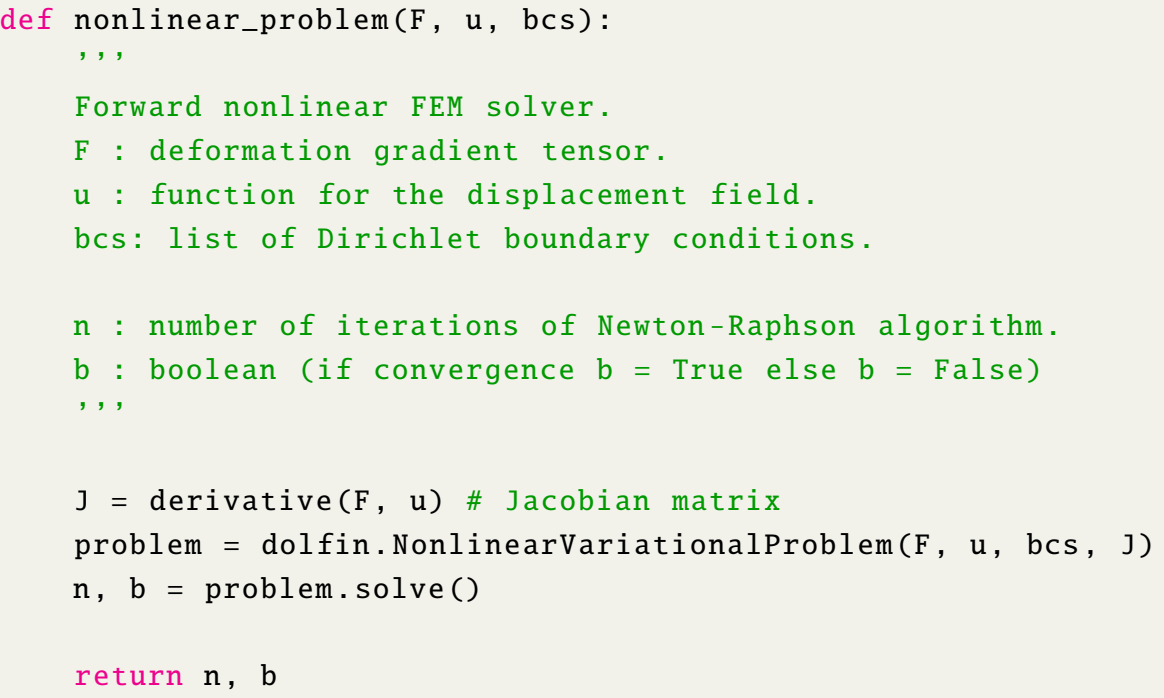

Algorithm 1: Implementation of variational formulation in FENICS

\subsubsection{Constitutive model}

According to Limbert's review [47], constitutive laws for skin (and this is the case of any biological material) can be classified into three categories: phenomenological, structural and structurally based phenomenological models. If one considers mechanical behavior only, a phenomenological model is a set of mathematical relations that describe the evolution of stress as a function of deformation gradient. Hence, it is generally always possible to fit such a constitutive model to a set of experimental data. This 'black box' approach has one major drawback: the resulting material parameters do not always have a direct physical interpretation and can be numerous. Moreover, it is usually difficult to choose the "best" law for a given situation, and, once this law has been identified, the best parameter set is non-unique and depends on boundary conditions. This was shown by Hauseux et al. [6] where the authors use an Holzapfel model and indicate, through a detailed sensitivity analysis that any boundary condition activates only some of the parameters. The compressible phenomenological model chosen here is the Gent model [55, 79].

Unlike more conventional phenomenological hyperelastic models with 2 parameters, such as NeoHookean, Mooney-Rivlin or Ogden-2, where the non-linear behavior occurs for relatively large deformations $\left(\lambda_{1}>2\right)$, the Gent model is a promising candidate to include non-linearities arising for small stretches $\left(\lambda_{1}<1.2\right)$ [62]. Other categories of constitutive models can be easily used in our numerical model.

The energy density for the healthy skin $\psi_{\mathrm{hs}}$ and for the keloid $\psi_{\mathrm{k}}$ are expressed in terms of four material parameters: $\mu_{\mathrm{hs}}$ and $J_{m \mathrm{hs}}$ for the healthy skin, $\mu_{\mathrm{k}}$ and $J_{m \mathrm{k}}$ for the keloid.

$$
\psi=-\frac{\mu}{2}\left(J_{m} \ln \left(1-\frac{I_{1}-3}{J_{m}}\right)+2 \ln (J)\right)
$$

$\mu$ and $J_{m}$ are the isotropic model parameters for each material, i.e., keloid and (healthy) skin, and $I_{1}$ is the first strain invariant. 


$$
I_{1}=\operatorname{tr}(\boldsymbol{B})=\operatorname{tr}\left(\boldsymbol{F} \boldsymbol{F}^{T}\right)=\lambda_{1}^{2}+\lambda_{2}^{2}+\lambda_{3}^{2}
$$

where $\boldsymbol{F}$ is the deformation gradient and $\left(\lambda_{i}\right)_{1 \leq i \leq 3}$ are the principal stretches.

The Gent model limits chain extensibility, which is characteristic of skin behaviour when stretched. The strain energy density expression is designed to be singular when the first invariant of $\boldsymbol{B}$, the left Cauchy-Green deformation tensor (also called the Piola deformation tensor), reaches a limiting value [80]:

$$
J_{m}<\lambda_{1}^{2}+\frac{2}{\lambda_{1}}-3
$$

The Gent strain energy function can be implemented very easily within our framework (Algorithm 2).

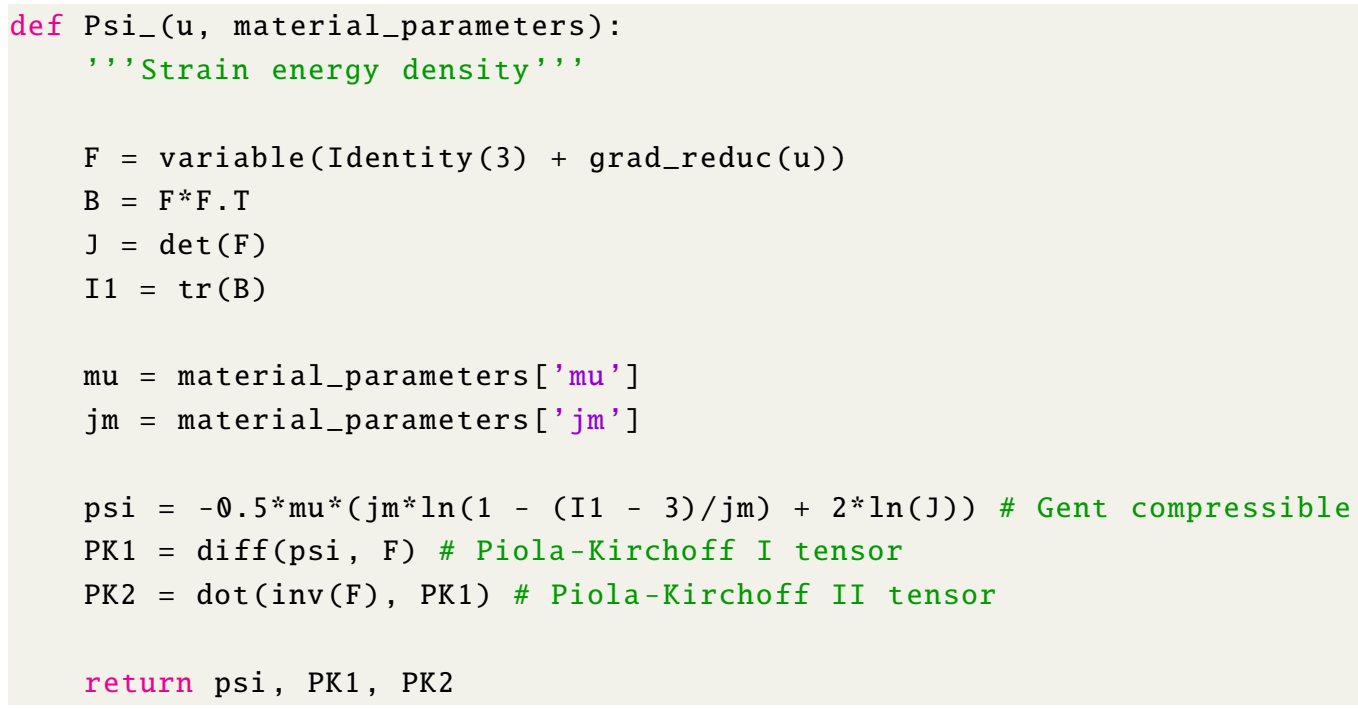

Algorithm 2: Implementation of constitutive model in FENICS

\subsection{Inverse identification}

Knowing experimental data at a set $\left\{t_{k}\right\}_{k=0,1, \ldots, N_{E}}$ with $t_{N_{E}}=T$, let's denote $u^{(k)}$ solution of direct problem (2) at time $t_{k}, \bar{u}^{(k)}$ prescribed displacement and $F_{\text {msr }}^{(k)}$ measured force magnitude at this time. We define the cost function quantifying relative discrepancy between between computed displacement field $\mathbf{u}^{(k)}$ and measured DIC displacement field $\mathbf{u}_{\mathrm{msr}}^{(k)}$ on restricted subdomain $\Omega_{\mathrm{msr}} \subset \Omega$ at every experimental time step :

$$
\mathcal{J}(\boldsymbol{\theta})=\frac{1}{2 N_{E}} \sum_{k=1}^{N_{E}} \frac{1}{\alpha^{2}}\left\|\mathbf{u}^{(k)}(\boldsymbol{\theta})-\mathbf{u}_{\mathrm{msr}}^{(k)}\right\|_{\Omega_{\mathrm{msr}}}^{2}
$$

where $\|\cdot\|_{\Omega_{\mathrm{msr}}}$ is a convenient norm defined as $\|\boldsymbol{U}\|_{\mathrm{msr}}^{2}=\int_{\Omega_{\mathrm{msr}}} \boldsymbol{U} \cdot \boldsymbol{U}^{T} d \boldsymbol{x}$.

$\alpha$ is a weighting coefficient used to scale misfit during time. A convenient way is to use experimental data :

$$
\alpha=\max _{k=0,1, \ldots, N_{E}}\left\|\mathbf{u}_{\mathrm{msr}}^{(k)}\right\|_{\Omega_{\mathrm{msr}}}
$$

To estimate bi-materials model parameters $\boldsymbol{\theta}=\left\{\mu_{\mathrm{k}}, J_{m \mathrm{k}}, \mu_{\mathrm{hs}}, J_{m \mathrm{hs}}\right\}$ from experimental test, one could 
find $\hat{\boldsymbol{\theta}}$ such as

$$
\mathcal{J}(\hat{\boldsymbol{\theta}})=\min _{\boldsymbol{\theta} \in \mathbb{R}^{N} \boldsymbol{J}} \mathcal{J}(\boldsymbol{\theta})
$$

As it's well-known that such problems are ill-posed, we add all available information in the minimization problem. Hence, we look for solution of Eq. 9 subject to the constraint that the mean of relative discrepancy between numerical and measured force magnitude should vanish :

$$
\mathcal{G}(\boldsymbol{\theta})=\frac{1}{N_{E}} \sum_{k=1}^{N_{E}} \frac{1}{\beta}\left(F_{x}^{(k)}-F_{\mathrm{msr}}^{(k)}\right)=0
$$

with scale parameter $\beta$ defined as :

$$
\beta=\max _{k=0,1, \ldots, N_{E}}\left|F_{\mathrm{msr}}^{(k)}\right|
$$

The predicted force $F_{x}^{(k)}$ is the $x$-component of the force vector oriented along the direction of uniaxial loading, and the latter is computed from the FEM solutions $\boldsymbol{u}^{(k)}$ by integrating the traction force $\boldsymbol{T}$ over the pad (Eq. 13] [81], while the measured forces $F_{\mathrm{msr}}^{(k)}$ are gathered from the deformation gauge for each load step (Fig. 11). $\Omega_{\mathrm{msr}}=\left\{\Omega_{1} \cup \Omega_{2}\right\}$ is a part of the domain $\Omega$ where the displacement field is measured (using Digital Image Correlation).

$$
\begin{gathered}
F_{x}^{(k)}=\int_{\Gamma_{\mathrm{Lpad}}} T_{x}^{(k)} d S \\
\boldsymbol{T}=\frac{\partial \psi\left(\boldsymbol{u}^{(k)}\right)}{\partial \boldsymbol{F}\left(\boldsymbol{u}^{(k)}\right)} \boldsymbol{N}
\end{gathered}
$$

Finally, $\Gamma$ is the boundary where the force is measured. $N$ and $d S$ are, respectively, unit normal and infinitesimal surface to that boundary in the reference configuration.

Then, to identify material parameters $\boldsymbol{\theta}=\left\{\mu_{\mathrm{k}}, J_{m \mathrm{k}}, \mu_{\mathrm{hs}}, J_{m \mathrm{hs}}\right\}$, we minimize cost function $J(\boldsymbol{\theta})$ subject to constraint $G(\boldsymbol{\theta})$ (10) using the Lagrange multiplier method. Adding a single Lagrange multiplier $\Lambda$, the unconstrained optimization problem is defined as [82,83]

$$
\hat{\boldsymbol{\theta}}=\underset{\boldsymbol{\theta}, \Lambda \in \mathbb{R}^{N} \theta^{+1}}{\operatorname{argmin}} \mathcal{J}(\boldsymbol{\theta})+\Lambda \mathcal{G}(\boldsymbol{\theta})
$$

Among several non-linear least squares methods [84], we choose the Newton-Gauss algorithm. This method is accurate and inexpensive provided that a good initial guess of the model parameters can be made.

\section{Numerical results}

\subsection{Mesh configuration}

\section{Reference mesh}

We built a number of finite element meshes, from coarse to fine. A mesh of $44 \mathrm{k}$ quadratic triangular elements (about $210^{5}$ DOFs) provides sufficient accuracy (Fig. 3 ) and is taken as a reference. Over the sensor area, we integrate the difference between the stress field provided by the reference mesh and that 

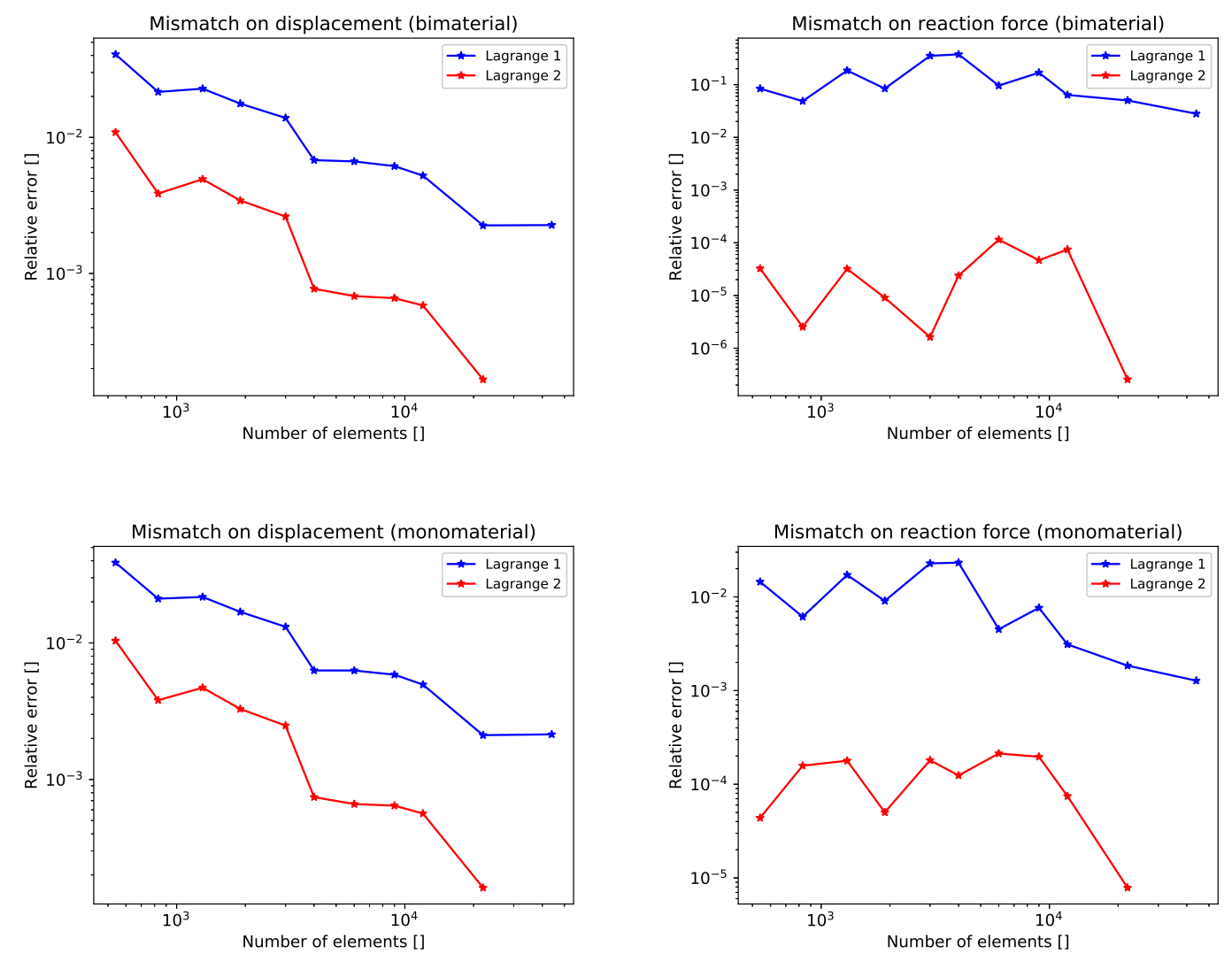

Figure 4: Reference mesh choice based on element degree and element size analysis of the forward nonlinear FEM solver. As the set reference mesh configurations are Lagrange 2 and 44k elements.

of a sequence of coarser meshes to understand the convergence of the discrete scheme (Fig. 4). We choose the material parameter set $\boldsymbol{\theta}_{\text {ref }}=\left\{\mu_{\mathrm{k}}=50 \mathrm{kPa} ; J_{m \mathrm{k}}=0.2 ; \mu_{\mathrm{hs}}=16 \mathrm{kPa} ; J_{m \mathrm{k}}=0.4\right\}$, based on our experience. Subscripts k and hs stand, respectively, for keloid and healthy-skin.

However, as shown in Figure (5), the direct nonlinear simulation is computationally costly if we project data on the reference mesh. As the convergence of the non-linear FEM solution scheme requires few iterations (200 iterations for 44k element mesh ), this large computational expense comes from the computational expense associated with number of DOF. Consequently, for practical simulations, we recommend using coarser (converged meshes) as reference meshes than the 44k element mesh shown above. The choice of this mesh is discussed in the following section.

\section{Optimized mesh}

Based on qualitative criteria (affordable computation cost and low discretization error), we design an "optima" coarse mesh by comparing nodal solutions with that of the reference mesh. We choose a 540element mesh, identify the high gradient zones, where we perform local, manual, adaptive refinement, to obtain a moderately fine mesh comprised of 1300 elements (Fig. 6, 7). As shown in Figure 8, the manually-refined mesh with 1300 elements is a suitable candidate for low-cost, yet accurate simulations. Note that it would be preferable to use a proper error indicator, as in [8,9.85].

Although the computations on the targeted mesh are fast and accurate, another criterion must be satisfied: parameter inverse identification accuracy regarding the discretization error. For that purpose, a first 

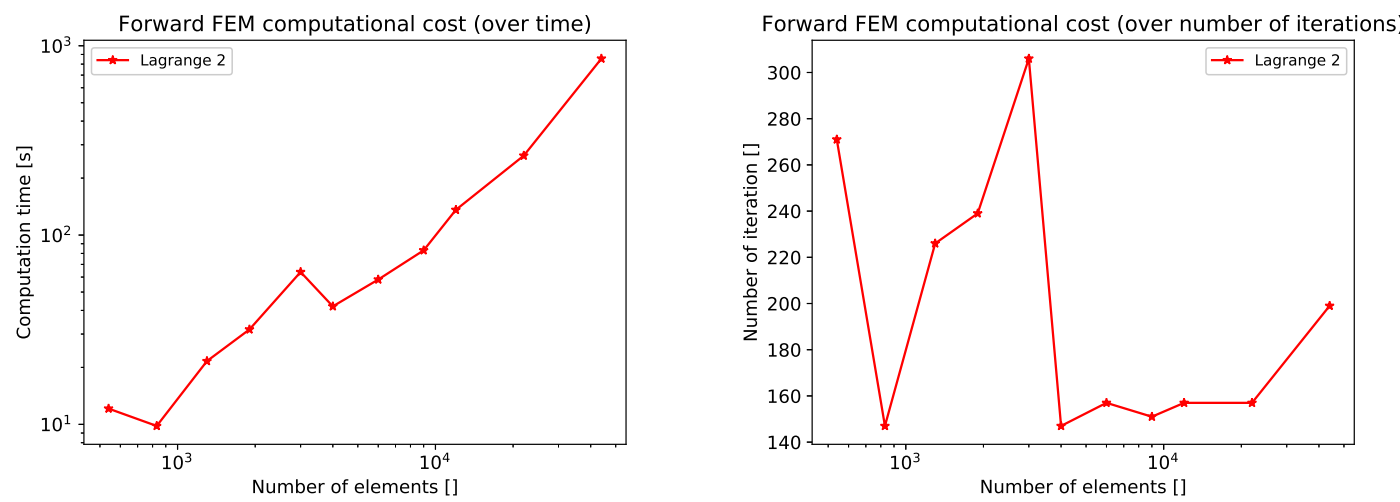

Figure 5: Computational costs of forward nonlinear simulation with different mesh element sizes.
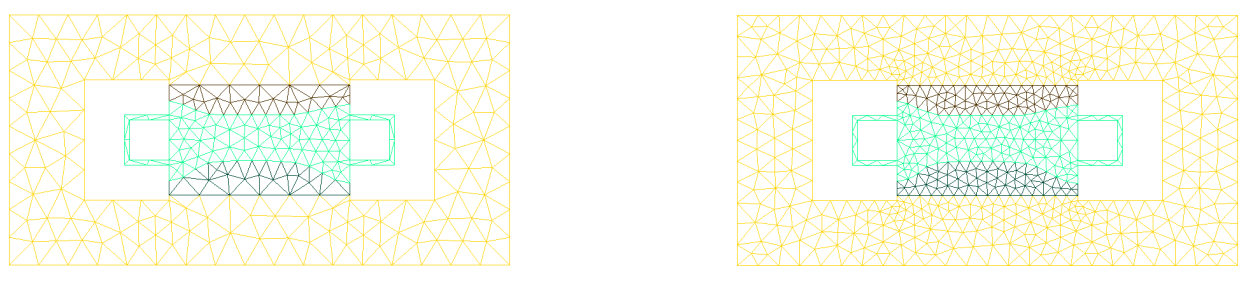

Figure 6: Coarsest operational meshes (left: 540 elements; right: 1300).

direct simulation with arbitrarily chosen material parameters (referential parameter set) is done with the reference mesh over 50 prescribed displacement sets from $0 \mathrm{~mm}$ to $4 \mathrm{~mm}$. Then, the output nodal solutions and the reaction force computed in post-treatment are introduced into the inverse solver as artificial targeted experimental data, where the optimization process is performed with a secondary coarser mesh. The initial guess fixed for all the cases is $\theta^{(0)}=\left\{\mu_{\mathrm{k}}^{(0)}=10 \mathrm{kPa} ; J_{m_{\mathrm{k}}}^{(0)}=0.01 ; \mu_{\mathrm{hs}}^{(0)}=\right.$ $\left.10 \mathrm{kPa} ; J_{m_{\mathrm{hs}}}{ }^{(0)}=0.01\right\}$. As the direct nonlinear solver converges over a small range of parameters with quadratic Lagrange elements, and conversely with linear Lagrange elements, the inverse identification is done on two sub-optimization steps: the converging set from the first optimization, using the first-guess $\theta^{(0)}$ and Lagrange-P1 elements, is used as a first-guess for a second optimization process with LagrangeP2 elements. Finally, we compare, versus the referential parameters, the identified material parameters to study the effect of the discretization on the inverse identification accuracy (Tab 11). From the latter table, we superpose in Figure (9) the accuracies of inverse identification for several mesh densities and their respective computation costs. As such, the optimized mesh proves to be a better trade-off between identification accuracy.

\subsection{Data noise sensitivity analysis}

We aim through this part to study parameter estimation accuracy with respect to variations of data noise levels occurring on measurements of reaction force and DIC fields. This study has two major objectives: validate the consistency of the numerical model and define the limit of measurement errors. Due to a lack of availability of experimental data, we have generated dummy data from a direct nonlinear FEM solver using the mesh reference (involving $44 \mathrm{k}$ Lagrange-P2 elements ) and the reference material parameters. Then for each observation time, additive white Gaussian noises (AWGN) are performed on 
Table 1: Effect of discretization error on inverse identification accuracy. The dummy data, relevant to the reference material parameters set are projected on several coarser meshes. k and hs stand respectively for "keloid" and "healthy-skin". Estimation accuracy is equal to $1-\varepsilon_{\theta}$, where $\varepsilon_{\theta}$ is the relative discrepancy between the estimated parameters and the reference $\boldsymbol{\theta}_{\text {ref }}$

\begin{tabular}{|c|c|c|c|}
\hline \multirow{2}{*}{$\begin{array}{c}\text { Mesh density } \\
\text { (number of elements) }\end{array}$} & \multicolumn{2}{|c|}{ Converging material parameters set } & \multirow{2}{*}{$\begin{array}{l}\text { Accuracy } \\
(\%)\end{array}$} \\
\hline & Lagrange-P1 & Lagrange-P2 & \\
\hline \multirow[t]{4}{*}{44000} & $\mu_{\mathrm{k}}=44.04 \mathrm{kPa}$ & $\mu_{\mathrm{k}}=50 \mathrm{kPa}$ & $100 \%$ \\
\hline & $J_{m \mathrm{k}}=0.2002$ & $J_{m \mathrm{k}}=0.2$ & $100 \%$ \\
\hline & $\mu_{\mathrm{hs}}=13.91 \mathrm{kPa}$ & $\mu_{\mathrm{hs}}=16 \mathrm{kPa}$ & $100 \%$ \\
\hline & $J_{m \mathrm{hs}}=0.406$ & $J_{m \mathrm{hs}}=0.4$ & $100 \%$ \\
\hline \multirow[t]{4}{*}{22000} & $\mu_{\mathrm{k}}=42.51 \mathrm{kPa}$ & $\mu_{\mathrm{k}}=50.038 \mathrm{kPa}$ & $99.92 \%$ \\
\hline & $J_{m \mathrm{k}}=0.2019$ & $J_{m \mathrm{k}}=0.2002$ & $99.92 \%$ \\
\hline & $\mu_{\mathrm{hs}}=13.19 \mathrm{kPa}$ & $\mu_{\mathrm{hs}}=16.022 \mathrm{kPa}$ & $99.86 \%$ \\
\hline & $J_{m \mathrm{hs}}=0.4042$ & $J_{m \mathrm{hs}}=0.3998$ & $99.95 \%$ \\
\hline \multirow[t]{4}{*}{12000} & $\mu_{\mathrm{k}}=41.432 \mathrm{kPa}$ & $\mu_{\mathrm{k}}=50.431 \mathrm{kPa}$ & $99.14 \%$ \\
\hline & $J_{m \mathrm{k}}=0.2006$ & $J_{m \mathrm{k}}=0.1999$ & $99.97 \%$ \\
\hline & $\mu_{\mathrm{hs}}=12.906 \mathrm{kPa}$ & $\mu_{\mathrm{hs}}=16.059 \mathrm{kPa}$ & $99.63 \%$ \\
\hline & $J_{m \mathrm{hs}}=0.4138$ & $J_{m \mathrm{hs}}=0.4015$ & $99.62 \%$ \\
\hline \multirow[t]{4}{*}{6000} & $\mu_{\mathrm{k}}=38.825 \mathrm{kPa}$ & $\mu_{\mathrm{k}}=50.52 \mathrm{kPa}$ & $98.96 \%$ \\
\hline & $J_{m \mathrm{k}}=0.2008$ & $J_{m \mathrm{k}}=0.2001$ & $99.95 \%$ \\
\hline & $\mu_{\mathrm{hs}}=12.265 \mathrm{kPa}$ & $\mu_{\mathrm{hs}}=16.166 \mathrm{kPa}$ & $98.96 \%$ \\
\hline & $J_{m \mathrm{hs}}=0.4166$ & $J_{m \mathrm{hs}}=0.4013$ & $99.68 \%$ \\
\hline \multirow[t]{4}{*}{1300} & $\mu_{\mathrm{k}}=36.358 \mathrm{kPa}$ & $\mu_{\mathrm{k}}=50.344 \mathrm{kPa}$ & $99.31 \%$ \\
\hline & $J_{m \mathrm{k}}=0.1931$ & $J_{m \mathrm{k}}=0.1971$ & $98.55 \%$ \\
\hline & $\mu_{\mathrm{hs}}=10.237 \mathrm{kPa}$ & $\mu_{\mathrm{hs}}=16.115 \mathrm{kPa}$ & $99.28 \%$ \\
\hline & $J_{m \mathrm{hs}}=0.4549$ & $J_{m \mathrm{hs}}=0.4133$ & $96.68 \%$ \\
\hline \multirow[t]{4}{*}{540} & $\mu_{\mathrm{k}}=40.37 \mathrm{kPa}$ & $\mu_{\mathrm{k}}=49.88 \mathrm{kPa}$ & $99.76 \%$ \\
\hline & $J_{m \mathrm{k}}=0.1949$ & $J_{m \mathrm{k}}=0.1923$ & $96.15 \%$ \\
\hline & $\mu_{\mathrm{hs}}=7.5 \mathrm{kPa}$ & $\mu_{\mathrm{hs}}=16.031 \mathrm{kPa}$ & $99.81 \%$ \\
\hline & $J_{m \mathrm{hs}}=0.491$ & $J_{m \mathrm{hs}}=0.4325$ & $91.88 \%$ \\
\hline \multirow[t]{4}{*}{ Optimized mesh } & $\mu_{\mathrm{k}}=44.101 \mathrm{kPa}$ & $\mu_{\mathrm{k}}=50.219 \mathrm{kPa}$ & $99.56 \%$ \\
\hline & $J_{m \mathrm{k}}=0.1988$ & $J_{m \mathrm{k}}=0.1994$ & $99.70 \%$ \\
\hline & $\mu_{\mathrm{hs}}=13.28 \mathrm{kPa}$ & $\mu_{\mathrm{hs}}=16.157 \mathrm{kPa}$ & $99.02 \%$ \\
\hline & $J_{m \mathrm{hs}}=0.431$ & $J_{m \mathrm{hs}}=0.4053$ & $99.68 \%$ \\
\hline
\end{tabular}



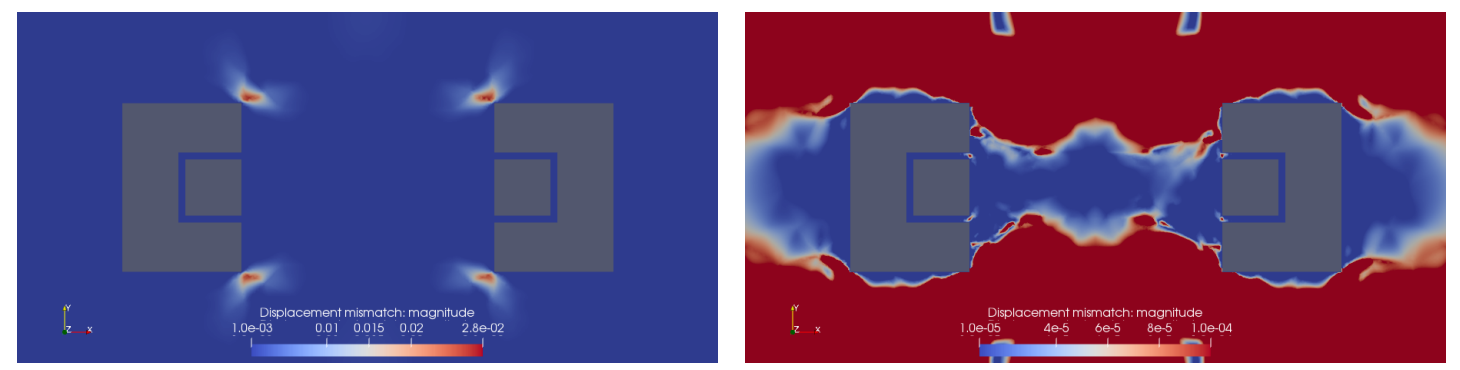

Figure 7: Relative displacement mismatch field between the coarsest mesh (540 cells) and the reference mesh (44k elements).
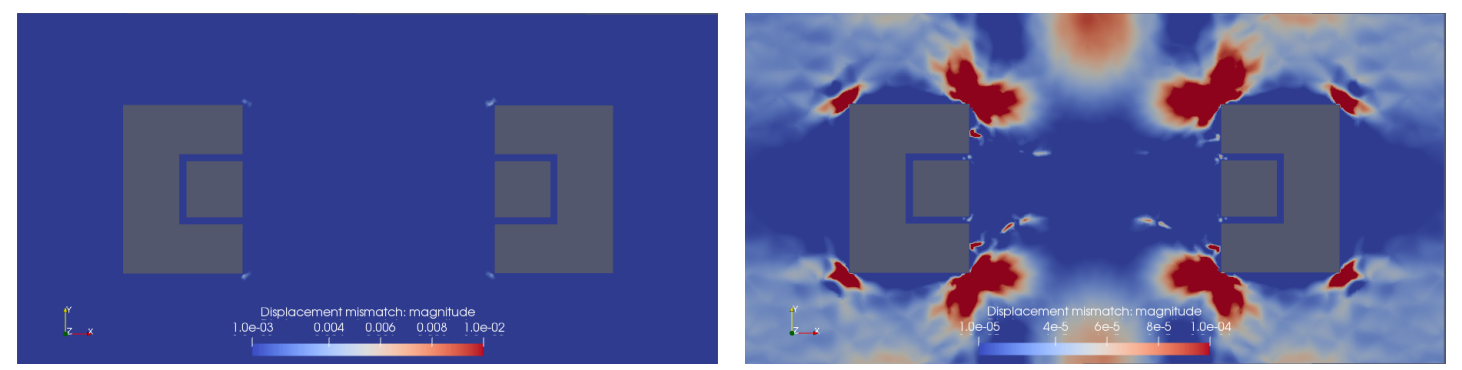

Figure 8: Relative displacement mismatch field between the adaptive-mesh (1300 cells) and the reference mesh (44k elements).

nodal solutions within the DIC observation zone and on the simulated reaction force (Fig. 10). The additive noise model has been employed frequently in many inverse studies [4, 86, 87]:

$$
\mathbf{u}_{\mathrm{msr}}=\mathbf{u}+S_{\mathrm{u}} \quad \forall X \in \Omega_{\mathrm{msr}}
$$

$$
F_{\mathrm{msr}}=F_{x}+S_{\mathrm{F}}
$$

with, respectively,

$$
S_{\mathrm{u}} \sim \mathcal{N}\left(0, S_{\text {DIC }}^{2}\right) \text { and } S_{\mathrm{F}} \sim \mathcal{N}\left(0, S_{\text {force }}^{2}\right)
$$

\subsubsection{Effect of double noise standard deviation}

The study has been done on 50 DIC frames relative to the incremental prescribed displacement of the moving pad from undeformed configuration to $4 \mathrm{~mm}$ traction. By varying separately standard deviations for both dummy displacement field and reaction force, $S_{\mathrm{DIC}}=\{0 ; 40 ; 120 ; 200\}(\mu \mathrm{m})$ and $S_{\text {force }}=\{0 ; 2 ; 6 ; 10\}(\mathrm{mN})$, we create 16 artificial data set to be input as experimental data into the inverse problem solver. In the meantime, we consider zero-noise cases to dissociate the effects of the two noise natures on parameter identification. As the study concerns the effect of noise on parameter estimation regardless the robustness of the inverse solver (convergence to a global optimum), and for computation cost reason, we set a same initial guess $\theta^{(0)}$ not further away from the targeted material parameters $\theta=\left\{\mu_{\mathrm{k}}=49 \mathrm{kPa} ; J_{m \mathrm{k}}=0.19 ; \mu_{\mathrm{hs}}=15 \mathrm{kPa} ; J_{m \mathrm{hs}}=0.39\right\}$.

We propose hereby numerical indicators, $\varepsilon_{\text {DIC }}$ and $\varepsilon_{\text {force }}$, to quantify the discrepancies caused by 


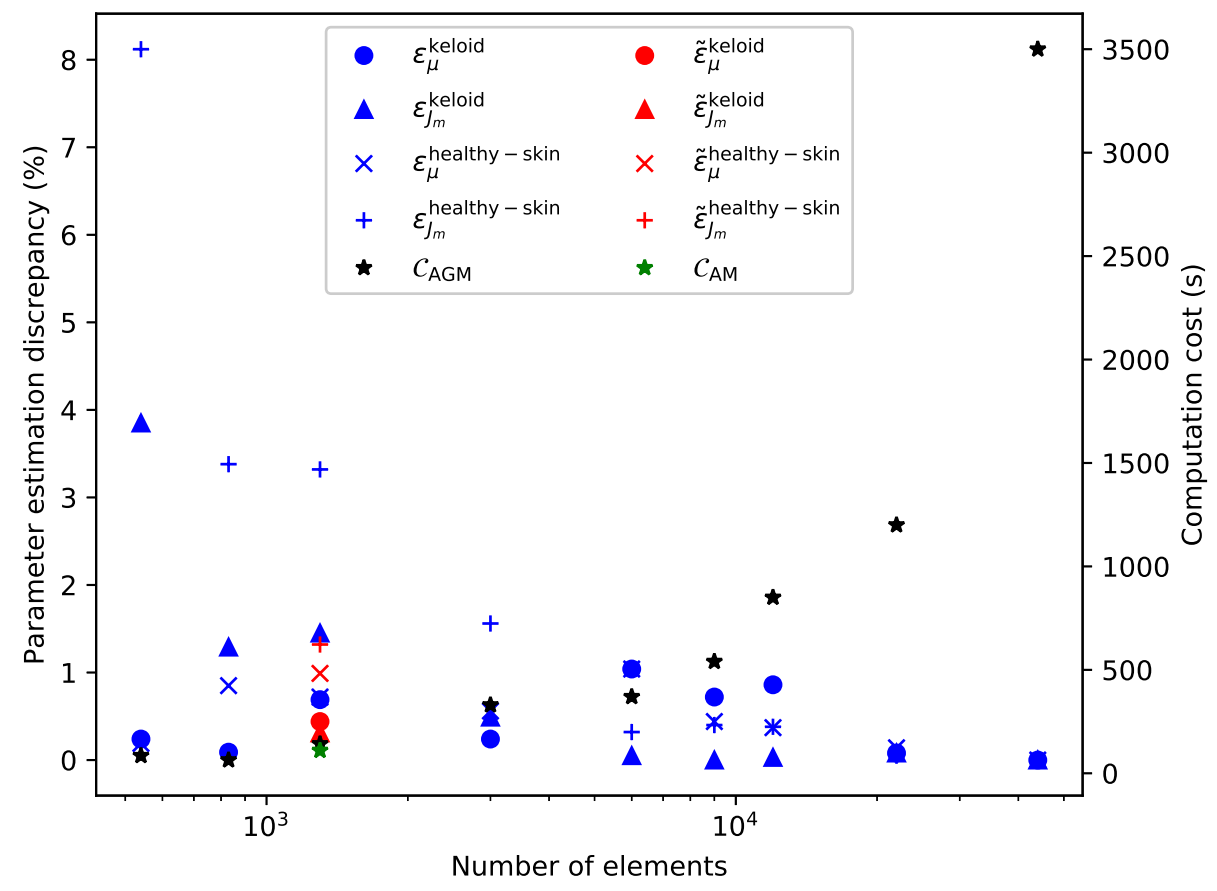

Figure 9: Quantification of parameter identification accuracy with respect to discretization error (Tab. 1) and computation cost. The estimation discrepancy for each material parameter, denoted by $\varepsilon$, is equal to its relative difference with $\boldsymbol{\theta}_{\text {ref }}$, on every mesh. $\tilde{\varepsilon}$ is particularly attributed to inverse identification over adaptive mesh. $C_{\mathrm{AGM}}$ and $C_{\mathrm{AM}}$ are inverse identification costs on, respectively, automatic-generated mesh and adaptive mesh. The optimized mesh witnesses a very good trade-off between discretization error and computation cost.

generating noises randomly around reference data overall observation times:

$$
\begin{gathered}
\varepsilon_{\mathrm{DIC}}=\frac{\sum_{k=1}^{50} \sqrt{\int_{\Omega}\left(\mathbf{u}_{\mathrm{ref}}^{(k)}-\mathbf{u}_{\mathrm{msr}}^{(k)}\right)^{2}}}{\sum_{k=1}^{50} \sqrt{\int_{\Omega} \mathbf{u}_{\mathrm{ref}}^{(k)^{2}}}} \\
\varepsilon_{\text {force }}=\frac{\sqrt{\sum_{k=1}^{50}\left(F_{\mathrm{msr}}^{(k)}-F_{\mathrm{ref}}^{(k)}\right)^{2}}}{\sqrt{\sum_{k=1}^{50} F_{\mathrm{ref}}^{(k)^{2}}}}
\end{gathered}
$$

The dummy data used for inverse identification are projected over two mesh configurations: the reference mesh, to deal only with noise-level effect, and the optimized mesh, to study the effect of discretization error combined with measurement noise. The results are respectively shown in Figure 11

\subsubsection{Effect of number of snapshots}

In this part, we analyze the effect of the amount of data, consisting of the DIC snapshots and their relative reaction forces, on the accuracy of parameter inverse identification. To do, from the full set of noisy dummy data, we select a subset of $N_{\mathrm{S}}$ snapshots distributed uniformly over the whole time range. Beside the weakly non-linear mechanical response scenario, where we set the referential material parameters to generate data, we propose to explore occasionally the effects of the number of snapshots 

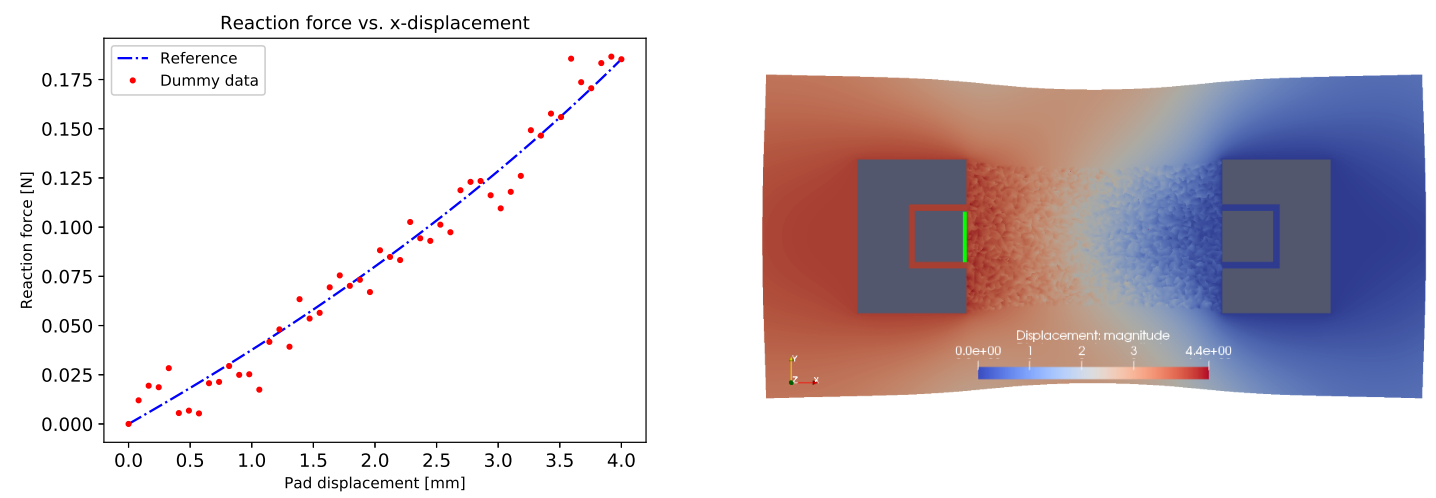

Figure 10: Generation of noised dummy data from reference solution.

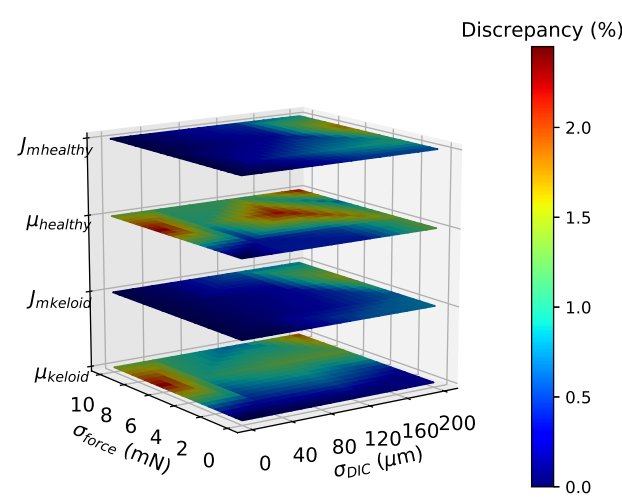

(a) Reference mesh (44000 cells)

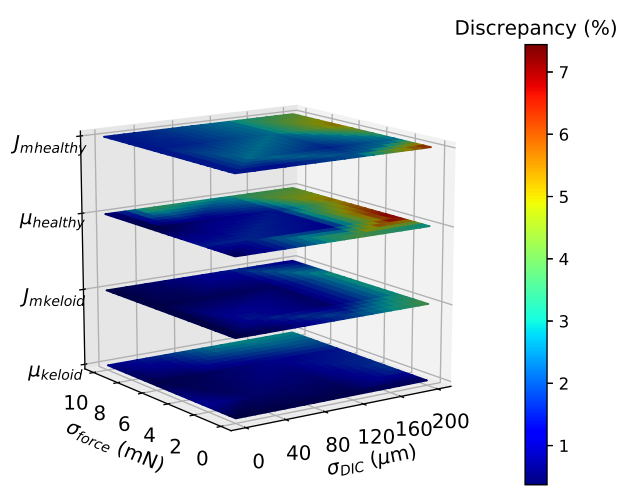

(b) Optimized mesh (1300 cells)

Figure 11: Parameter estimation accuracy performed on noisy dummy data, with different levels, projected over studied meshes. As the noise distribution is based on randomness, we need to draw three times the dummy data samples and gather the maximum discrepancies. All the values are taken from Tables 2 and 3 (Appendix A).

$\left(N_{\mathrm{S}}\right)$ in case of highly non-linear behavior also. The latter is secured by fixing the top and bottom external boundaries in the y-direction and by setting the following parameter in the FEM solver as $\theta=\left\{\mu_{\mathrm{k}}=10 \mathrm{kPa} ; J_{m \mathrm{k}}=0.017 ; \mu_{\mathrm{hs}}=8 \mathrm{kPa} ; J_{m \mathrm{k}}=0.17\right\}$. The dummy noise are fabricated for both scenarios basing on AWGN theory with the same standard deviations $S_{\text {DIC }}=200 \mu \mathrm{m}$ and $S_{\text {force }}=20 \mathrm{mN}$. To quantify noises only over the pseudo-times subsets, we use modified indicators $\hat{\varepsilon}_{\text {DIC }}$ and $\hat{\varepsilon}_{\text {force }}$. In Figure 12, we illustrate all the results related to the inverse identification inaccuracies for three random draws.

\subsection{Objective function}

We study in this part the ability to identify material parameters if the optimization is set only on displacement or forces. Hence, The displacement fields mismatch term is uncoupled from reaction forces in the constrained equation 14. We obtain two alternative optimization expressions that have been tested out in the present study (Eq. 20 and 21). Consequently, the Lagrange multiplier $\Lambda$ is not taken into account. We also aim, through this isolation procedure, to correlate separately the nature of data-displacement measurement within the ZOI or reaction force over the pad- to each of parameter. In Figure 14, the evolution of material parameters for each optimization iteration for all constrained cost functions (Eq. 14, 20 and 21) is shown. As result, the constrained optimization cost $\mathcal{T}+\lambda \mathcal{G}$ is the only 


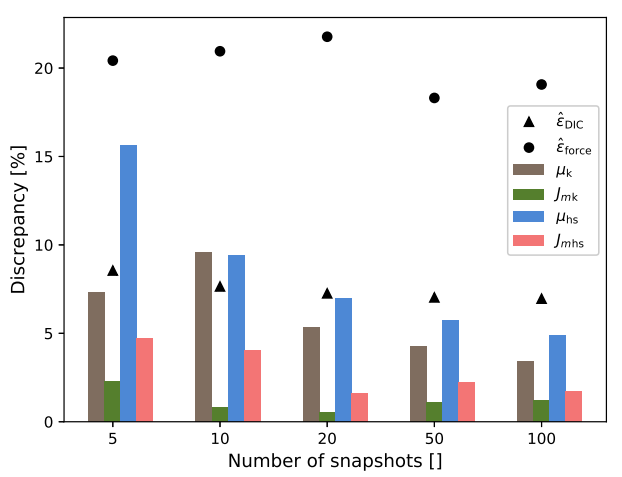

(a) Weakly non-linear

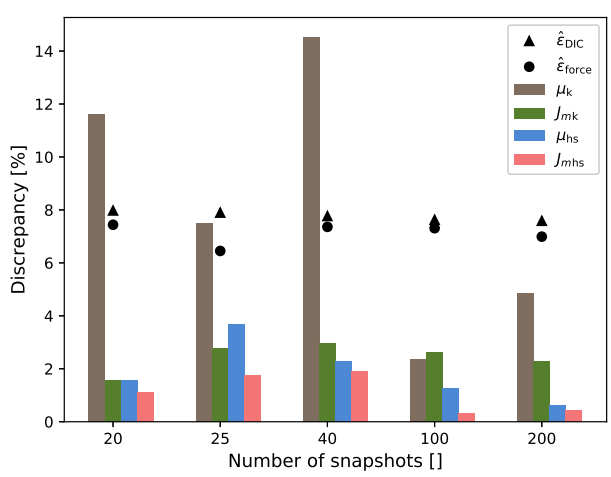

(b) Highly non-linear

Figure 12: Identification sensitivity to measurement noise with respect to $N_{\mathrm{S}}$. The dummy data are projected on a 44k-elements-mesh (reference). As the noise distribution is based on randomness, we need to draw three times the dummy data samples and keep the maximum discrepancies. All the values are taken from Table 4 (Appendix A].
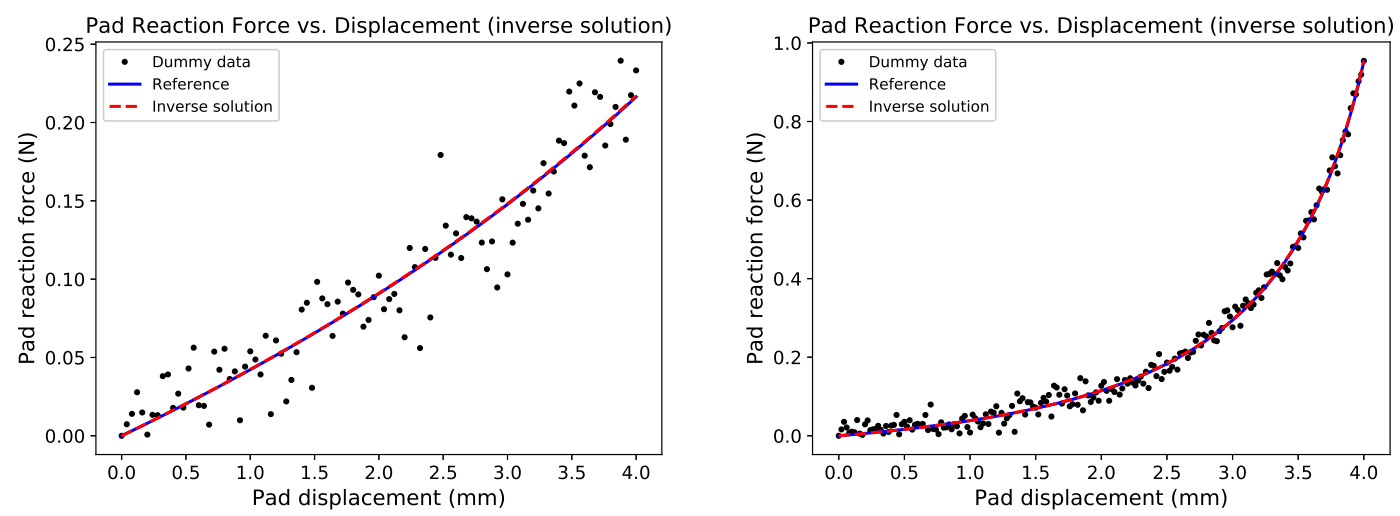

Figure 13: Inverse solutions computed from dummy weakly and highly nonlinear FD-curve data. All the snapshots were used to estimate the material parameters. All the other inverse solutions with respect to the number of observation pseudo-times are detailed in Appendix B.

tool to identify the targeted materials $\boldsymbol{\theta}_{\text {ref. }}$. Or more specifically, to estimate all the material parameters of bi-materials, both displacement and reaction forces must be measured and used in the minimization process.

$$
\begin{gathered}
\mathcal{J}_{\mathrm{u}}(\boldsymbol{\theta})=\frac{1}{2} \frac{1}{N_{E}} \sum_{k=1}^{N_{E}} \frac{1}{\alpha^{2}}\left\|\mathbf{u}^{(k)}(\boldsymbol{\theta})-\mathbf{u}_{\mathrm{msr}}^{(k)}\right\|_{\Omega_{\mathrm{msr}}}^{2} \\
\mathcal{J}_{\mathrm{f}}(\boldsymbol{\theta})=\frac{1}{N_{E}} \sum_{k=1}^{N_{E}} \frac{1}{\beta}\left(F_{x}^{(k)}-F_{\mathrm{msr}}^{(k)}\right)
\end{gathered}
$$

An alternative constrained objective function $\mathcal{J}_{\text {uf }}$ (Eq. 22) have been also proposed. In this equation, the force mismatch is squared and is not multiplied by the Lagrange multiplier $\Lambda$. For derivation purpose, we add the coefficient $1 / 2$. The results have shown that this optimization equation, used frequently in many characterization studies, is capable to identify correctly the material parameters but only in monolithic case. Also, it is technically not possible to derive automatically the square integral in FENICS. A 
manual implementation of the sensitivity equation is doable but highly expensive: the Hessian matrix is assembled over mesh nodes for each snapshot.

$$
\mathcal{J}_{\mathrm{uf}}(\boldsymbol{\theta})=\frac{1}{2} \frac{1}{N_{E}} \sum_{k=1}^{N_{E}} \frac{1}{\alpha^{2}}\left\|\mathbf{u}^{(k)}(\boldsymbol{\theta})-\mathbf{u}_{\mathrm{msr}}^{(k)}\right\|_{\Omega_{\mathrm{msr}}}^{2}+\frac{1}{2} \frac{1}{N_{E}} \sum_{k=1}^{N_{E}} \frac{1}{\beta^{2}}\left(F_{x}^{(k)}-F_{\mathrm{msr}}^{(k)}\right)^{2}
$$

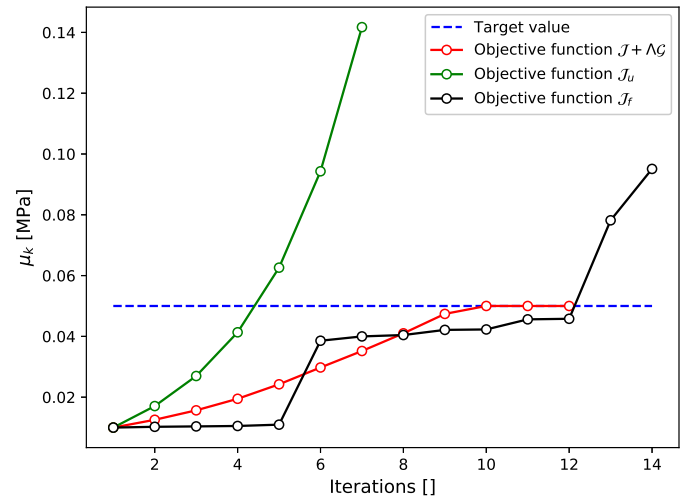

(a) $\mu_{\mathrm{k}}$ parameter

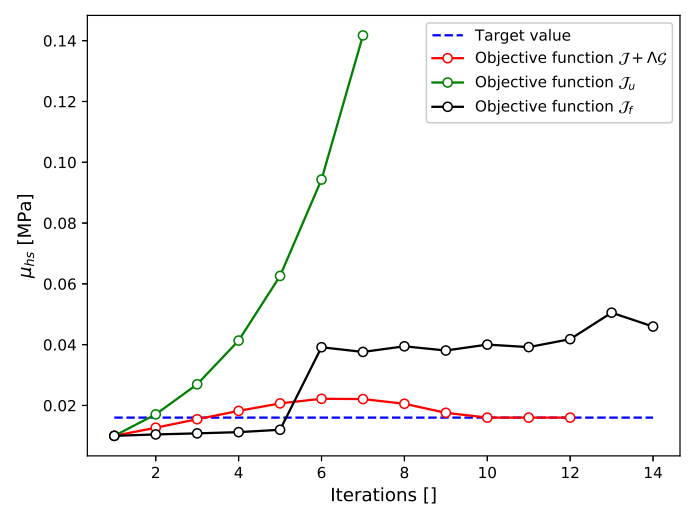

(c) $\mu_{\mathrm{hs}}$ parameter

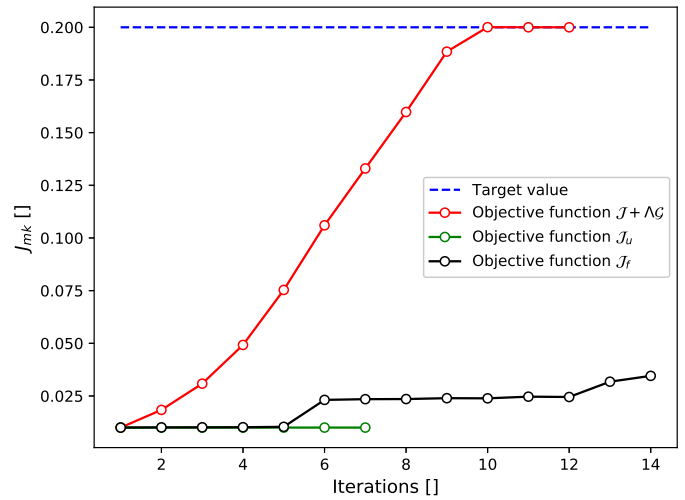

(b) $J_{m \mathrm{k}}$ parameter

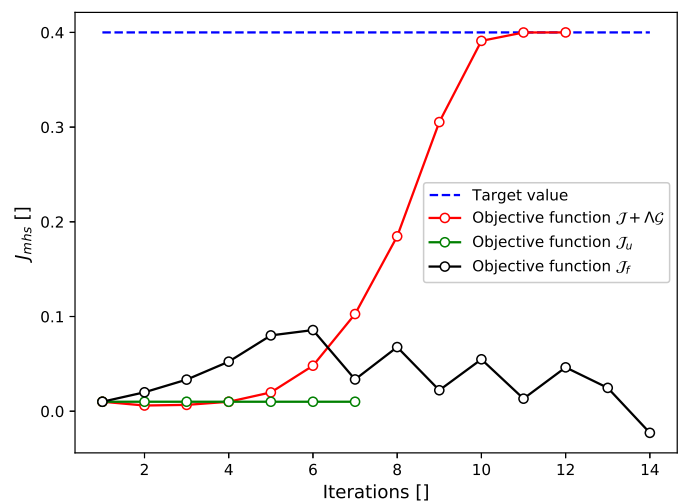

(d) $J_{m \mathrm{hs}}$ parameter

Figure 14: Convergence of material parameters for different cost functions.

\section{Discussion}

In Figure 4, we observe the non-convergence of FEM solutions in terms of element degree (relative error $>1 \%$ ): the use of Lagrange-P1 element demonstrates also its incapacity to estimate accurately the reference material parameters (Tab. 1), even when using projected artificial data on highly refined mesh (reference mesh). However, the results have shown that the initial guess of parameters set in the inverse solver can be relatively very far from the reference parameter in case of Lagrange-P1 interpolation, i.e. $\frac{\theta_{\text {target }}}{\theta^{(0)}} \approx 40$. And in case of Lagrange-P2 interpolation, setting the same initial guess occurs in costly computations and most of time in non-convergence of direct Newton-Raphson algorithm. Therefore, as illustrated in Table 1. we have used strategically both linear and quadratic interpolation in two suboptimization steps to identify successfully the targeted parameter set. Starting from a far initial guess, where the linear elements are used, a first set is estimated. Then by taking the latter as an initial guess into the inverse solver, based on quadratic finite elements, the final parameter set is correctly identified. For example, $J_{m_{\mathrm{hs}}}{ }^{(0)}=0.01 \rightarrow J_{m_{\mathrm{hs}}}^{\text {Lagrange-P1 }}=0.406 \rightarrow J_{m_{\mathrm{hs}}}^{\text {Lagrange-P2 }}=J_{m_{\mathrm{hs}}}^{\text {reference }}=0.4$. As far as 
we authors know, this strategy has never been used before. Commonly, the choice of FEM element shape function is arbitrary providing that it secures a successful convergence. Though, using linear or quadratic elements may lead to different local optimums. Besides, if one assumes that the quadratic elements represent better the captured DIC field, the 'double-trigger' technique would be a good way to converge to the most accurate parameter set.

The correlations between material parameters and uncertainty natures, measurement noise and discretization errors, separately and combined, are discussed hereby. Firstly, to deal only with the measurement uncertainty factor, the dummy data have been projected on the reference mesh. Globally, the relative mismatches of identified parameters are remarkably low $(<2.5 \%)$ for noise levels reaching up to $\varepsilon_{\text {DIC }}=8 \%$ and $\varepsilon_{\text {force }}=12 \%$ (Fig. 11a). Once applying only noises effect on forces $\left(\varepsilon_{\text {DIC }}=0 \mu \mathrm{m}\right)$, we notice that identification of $J_{m \mathrm{k}}$ and $J_{m \mathrm{hs}}$ still be perfectly accurate. Consequently, $\mu_{\mathrm{k}}$ and $\mu_{\mathrm{hs}}$ are tightly related to the sensitivity of reaction force. Also, $\mu_{\mathrm{k}}$ is as sensitive as $\mu_{\mathrm{hs}}$ to force noise. It would be explained that because of zero-noise on DIC data, the objective function (Eq. 14) is reduced to its force part, where the bi-material is interpreted as a homogeneous media. Inversely, by focusing only on displacement noises $\left(\varepsilon_{\text {force }}=0 \mathrm{mN}\right)$, we observe that all parameters discrepancies, more importantly $J_{m \mathrm{k}}$ and $J_{m \mathrm{hs}}$, increase for higher noise level on DIC (Fig. 11a). Finally, the combination of both DIC and forces measurement noise does not lead to higher mismatches as expected, and the maximum parameter discrepancy is below 2.5\%. For more details, see Table 3 in Appendix A

Then, we discuss the effect of discretization errors on inverse identification accuracy (Fig. 11b). As the data are projected on a coarser adaptive mesh, the discrepancies of identified parameters increase higher $\varepsilon_{\theta}<7.44 \%$. For all double noise levels, the relative mismatches of keloid parameters $\mu_{\mathrm{k}}$ and $J_{m \mathrm{k}}$ are likely very low $(<1 \%)$, except for some critical cases where it reaches $(4 \%)$. The other parameters, $\mu_{\mathrm{hs}}$ and $J_{m \mathrm{hs}}$, are seemingly more sensitive to the combination measurement-noise/discretization-error, with a critical discrepancy approximating $7.5 \%$. It is because many nodes are deleted in the coarser mesh, and especially outside the keloid scar, where the nodal solutions are spatially sensitive (because of significant transverse deformation gradient). Thus, we conclude that the proposed optimized coarser mesh is suitable for fast and accurate computations, knowing that the displacements and reaction forces are assessed with low uncertainty levels: $S_{\text {DIC }}<120 \mu \mathrm{m}$ and $S_{\text {force }}<10 \mathrm{mN}$. In critical cases, we may push uncertainty limits of displacement measurement to $S_{\mathrm{DIC}}<200 \mu \mathrm{m}$ and extend at the same time the ZOI edges towards top and bottom external boundaries (Fig. 1). This study helps us to control efficiently further experimental protocols. However, in the case of DIC processing, it is not obvious to quantify uncertainties, because they depend on many parameters, such as subset size, correlation window size and focal length of the optical system [88].

Additionally, the analysis of inverse identification sensitivity with respect to the number of observation times have been done. In Figure 12, we see that adding more DIC snapshots results in decreasing estimation error value $\hat{\varepsilon}_{D I C}$ in both cases, highly and weakly nonlinear mechanical response. With few snapshots, it would be also possible to identify accurately the parameters if relative points are concentrated on the curving part. However, within the logic of real-time error estimation method for surgical simulation [8,9], a manual selection of snapshots is out of interest. Through the obtained results, a challenging compromise between number of equidistant observation times and CPU cost (central processing unit) should be carried on. Basing on sensitivity study in both cases, highly and weakly non-linear behaviors, choosing around 100 equidistant observation times would be a better option. It must be taken into account that our choice depends on the structure and the constitutive model. If our open-source framework is used for another soft tissue study, i.e. artery, a quick sensitivity 


\section{References}

[1] H. Rappel, L. A. A. Beex, J. S. Hale, L. Noels, and S. P. A. Bordas, "A tutorial on Bayesian inference to identify material parameters in solid mechanics," Archives of Computational Methods in Engineering, vol. 27, no. 2, pp. 361-385, 2020.

[2] T. Ritto and L. Nunes, "Bayesian model selection of hyperelastic models for simple and pure shear at large deformations," Computers \& Structures, vol. 156, pp. $101-109,2015$.

[3] S. Madireddy, B. Sista, and K. Vemaganti, "A bayesian approach to selecting hyperelastic constitutive models of soft tissue," Computer Methods in Applied Mechanics and Engineering, vol. 291, pp. 102 - 122, 2015.

[4] H. Rappel, L. A. A. Beex, J. S. Hale, and S. P. A. Bordas, "Bayesian inference for the stochastic identification of elastoplastic material parameters: introduction, misconceptions and insights," arXiv preprint arXiv:1606.02422, 2016.

[5] H. Rappel, L. A. A. Beex, and S. P. A. Bordas, "Bayesian inference to identify parameters in viscoelasticity," Mechanics of Time-Dependent Materials, vol. 22, no. 2, pp. 221-258, 2018. 
[6] P. Hauseux, J. S. Hale, S. Cotin, and S. P. Bordas, "Quantifying the uncertainty in a hyperelastic soft tissue model with stochastic parameters," Applied Mathematical Modelling, vol. 62, pp. 86 - 102, 2018.

[7] P. Hauseux, J. S. Hale, and S. P. Bordas, "Accelerating Monte Carlo estimation with derivatives of high-level finite element models," Computer Methods in Applied Mechanics and Engineering, vol. 318, pp. 917 - 936, 2017.

[8] H. P. Bui, S. Tomar, H. Courtecuisse, M. Audette, S. Cotin, and S. P. A. Bordas, "Controlling the error on target motion through real-time mesh adaptation: Applications to deep brain stimulation," International Journal for Numerical Methods in Biomedical Engineering, vol. 34, no. 5, p. e2958, 2018.

[9] H. P. Bui, S. Tomar, H. Courtecuisse, S. Cotin, and S. P. A. Bordas, "Real-time error control for surgical simulation," IEEE Transactions on Biomedical Engineering, vol. 65, pp. 596-607, March 2018.

[10] N. W. Schulmann, S. Cotin, and I. Peterlík, "The effect of discretization on parameter identification. Application to patient-specific simulations," in CMBBE 2019 - 16th International Symposium on Computer Methods in Biomechanics and Biomedical Engineering, (New York (NY), United States), Aug. 2019.

[11] M. Duprez, S. P. A. Bordas, M. Bucki, H. P. Bui, F. Chouly, V. Lleras, C. Lobos, A. Lozinski, P.-Y. Rohan, and S. Tomar, "Quantifying discretization errors for soft tissue simulation in computer assisted surgery: A preliminary study," Applied Mathematical Modelling, vol. 77, pp. 709-723, 2020.

[12] S. Cotin, H. Delingette, and N. Ayache, "Real-time elastic deformations of soft tissues for surgery simulation," IEEE Transactions on Visualization and Computer Graphics, vol. 5, no. 1, pp. 62-73, 1999.

[13] H. Courtecuisse, J. Allard, P. Kerfriden, S. P. A. Bordas, S. Cotin, and C. Duriez, "Real-time simulation of contact and cutting of heterogeneous soft-tissues," Medical Image Analysis, vol. 18, no. 2, pp. 394 - 410, 2014.

[14] N. Haouchine, J. Dequidt, I. Peterlik, E. Kerrien, M.-O. Berger, and S. Cotin, "Image-guided simulation of heterogeneous tissue deformation for augmented reality during hepatic surgery," in 2013 IEEE international symposium on mixed and augmented reality (ISMAR), pp. 199-208, IEEE, 2013.

[15] N. Haouchine, S. Cotin, I. Peterlik, J. Dequidt, M. S. Lopez, E. Kerrien, and M. Berger, "Impact of soft tissue heterogeneity on augmented reality for liver surgery," IEEE Transactions on Visualization and Computer Graphics, vol. 21, no. 5, pp. 584-597, 2015.

[16] C. J. Paulus, N. Haouchine, S.-H. Kong, R. V. Soares, D. Cazier, and S. Cotin, "Handling topological changes during elastic registration,” International journal of computer assisted radiology and surgery, vol. 12, no. 3, pp. 461-470, 2017.

[17] S. Avril, M. Bonnet, A.-S. Bretelle, M. Grédiac, F. Hild, P. Ienny, F. Latourte, D. Lemosse, S. Pagano, E. Pagnacco, and F. Pierron, "Overview of identification methods of mechanical parameters based on full-field measurements," Experimental Mechanics, vol. 48, p. 381, Jul 2008.

[18] P. Ienny, A.-S. Caro-Bretelle, and E. Pagnacco, "Identification from measurements of mechanical fields by finite element model updating strategies," European Journal of Computational Mechanics, vol. 18, no. 3-4, pp. 353-376, 2009.

[19] M. Grédiac, F. Hild, and A. Pineau, eds., Full-Field Measurements and Identification in Solid Mechanics. John Wiley \& Sons, Inc., Dec. 2012.

[20] K. T. Kavanagh and R. W. Clough, "Finite element applications in the characterization of elastic solids," International Journal of Solids and Structures, vol. 7, no. 1, pp. 11 - 23, 1971.

[21] T. J. Keating, P. Wolf, and F. Scarpace, “An improved method of digital image correlation,” Photogrammetric Engineering and Remote Sensing, vol. 41, no. 8, pp. 993-1002, 1975.

[22] F. Rouger, M. Khebibeche, and C. Le Govic, "Non determined tests as a way to identify wood elastic parameters the finite element approach," in Mechanical Identification of Composites, pp. 82-90, Springer, 1991.

[23] J. Molimard, R. L. Riche, A. Vautrin, and J. R. Lee, "Identification of the four orthotropic plate stiffnesses using a single open-hole tensile test," Experimental Mechanics, vol. 45, pp. 404-411, Oct. 2005.

[24] D. Lecompte, A. Smits, H. Sol, J. Vantomme, and D. V. Hemelrijck, "Mixed numerical-experimental technique for orthotropic parameter identification using biaxial tensile tests on cruciform specimens," International Journal of Solids and Structures, vol. 44, pp. 1643-1656, Mar. 2007.

[25] L. Allais, M. Bornert, T. Bretheau, and D. Caldemaison, "Experimental characterization of the local strain field in a heterogeneous elastoplastic material," Acta Metallurgica et materialia, vol. 42, no. 11, pp. 3865-3880, 1994.

[26] M. Meuwissen, An inverse method for the mechanical characterisation of metals. PhD thesis, Technische Universiteit Eindhoven, Eindhoven, 1998. 
[27] M. Meuwissen, C. Oomens, F. Baaijens, R. Petterson, and J. Janssen, "Determination of the elasto-plastic properties of aluminium using a mixed numerical-experimental method," Journal of Materials Processing Technology, vol. 75, pp. 204-211, Mar. 1998.

[28] F. Mathieu, H. Leclerc, F. Hild, and S. Roux, "Estimation of elastoplastic parameters via weighted FEMU and integratedDIC," Experimental Mechanics, vol. 55, pp. 105-119, May 2014.

[29] L. Lemagourou, F. Bos, and F. Rouger, "Identification of constitutive laws for wood-based panels by means of an inverse method," Composites Science and Technology, vol. 62, pp. 591-596, Mar. 2002.

[30] M. Giton, A.-S. Caro-Bretelle, and P. Ienny, "Hyperelastic behaviour identification by a forward problem resolution: Application to a tear test of a silicone-rubber," Strain, vol. 42, pp. 291-297, Nov. 2006.

[31] K. Genovese, L. Lamberti, and C. Pappalettere, "Mechanical characterization of hyperelastic materials with fringe projection and optimization techniques," Optics and Lasers in Engineering, vol. 44, no. 5, pp. 423 - 442, 2006.

[32] J. Zhao, J. Dong, Z. Liu, and H. Xie, "Characterization method of mechanical properties of rubber materials based on in-situ stereo finite-element-model updating," Polymer Testing, vol. 79, p. 106015, 2019.

[33] W. Maurel, D. Thalmann, Y. Wu, and N. M. Thalmann, Biomechanical models for soft tissue simulation, vol. 48. Springer, 1998.

[34] G. A. Holzapfel, "Biomechanics of soft tissue," in Handbook of Materials Behavior Models, vol. 3, pp. 1057-1071, Academic Press San Diego, USA, 2001.

[35] S. Avril and S. Evans, eds., Material Parameter Identification and Inverse Problems in Soft Tissue Biomechanics. Springer International Publishing, 2017.

[36] M. Zhang, Y. Zheng, and A. F. Mak, "Estimating the effective young's modulus of soft tissues from indentation tests-nonlinear finite element analysis of effects of friction and large deformation," Medical Engineering Physics, vol. 19 , no. 6 , pp. $512-517,1997$.

[37] R. Meijer, L. F. A. Douven, and C. W. J. Oomens, "Characterisation of anisotropic and non-linear behaviour of human skin in vivo," Computer Methods in Biomechanics and Biomedical Engineering, vol. 2, no. 1, pp. 13-27, 1999.

[38] S. L. Evans and C. A. Holt, "Measuring the mechanical properties of human skin in vivo using digital image correlation and finite element modelling," The Journal of Strain Analysis for Engineering Design, vol. 44, no. 5, pp. 337-345, 2009.

[39] G. A. Holzapfel, T. C. Gasser, and R. W. Ogden, "A new constitutive framework for arterial wall mechanics and a comparative study of material models," Journal of elasticity and the physical science of solids, vol. 61, no. 1-3, pp. 1-48, 2000 .

[40] S. Avril, P. Badel, and A. Duprey, "Anisotropic and hyperelastic identification of in vitro human arteries from full-field optical measurements," Journal of Biomechanics, vol. 43, pp. 2978-2985, Nov. 2010.

[41] D. Schwenninger, S. Schumann, and J. Guttmann, "In vivo characterization of mechanical tissue properties of internal organs using endoscopic microscopy and inverse finite element analysis," Journal of biomechanics, vol. 44, no. 3, pp. 487-493, 2011.

[42] A. Bel-Brunon, S. Kehl, C. Martin, S. Uhlig, and W. Wall, "Numerical identification method for the non-linear viscoelastic compressible behavior of soft tissue using uniaxial tensile tests and image registration - application to rat lung parenchyma," Journal of the Mechanical Behavior of Biomedical Materials, vol. 29, pp. 360-374, Jan. 2014.

[43] J.-H. Kim, P. Badel, A. Duprey, J. P. Favre, and S. Avril, "Characterisation of failure in human aortic tissue using digital image correlation," Computer Methods in Biomechanics and Biomedical Engineering, vol. 14, pp. 73-74, Aug. 2011.

[44] D. Zhang and D. D. Arola, "Applications of digital image correlation to biological tissues," Journal of Biomedical Optics, vol. 9, no. 4, p. 691, 2004.

[45] M. Palanca, G. Tozzi, and L. Cristofolini, "The use of digital image correlation in the biomechanical area: a review," International Biomechanics, vol. 3, pp. 1-21, Dec. 2015.

[46] C. Wex, S. Arndt, A. Stoll, C. Bruns, and Y. Kupriyanova, "Isotropic incompressible hyperelastic models for modelling the mechanical behaviour of biological tissues: a review," Biomedizinische Technik. Biomedical engineering, vol. 60, p. 577-592, December 2015.

[47] G. Limbert, "Mathematical and computational modelling of skin biophysics: a review," Proceedings of the Royal Society A: Mathematical, Physical and Engineering Sciences, vol. 473, no. 2203, pp. 1-39, 2017. 
[48] J. M. Benítez and F. J. Montáns, "The mechanical behavior of skin: Structures and models for the finite element analysis," Computers Structures, vol. 190, pp. 75 - 107, 2017.

[49] G. Limbert, ed., Skin Biophysics. Springer International Publishing, 2019.

[50] G. Marckmann and E. Verron, "Comparison of hyperelastic models for rubber-like materials," Rubber chemistry and technology, vol. 79, no. 5, pp. 835-858, 2006.

[51] L. R. G. Treloar, "The elasticity of a network of long-chain molecules-II,” Trans. Faraday Soc., vol. 39, pp. 241-246, 1943.

[52] R. Rivlin, "Large elastic deformations of isotropic materials IV. Further developments of the general theory," Philosophical Transactions of the Royal Society of London. Series A, Mathematical and Physical Sciences, vol. 241, no. 835, pp. 379-397, 1948.

[53] R. W. Ogden and R. Hill, "Large deformation isotropic elasticity: on the correlation of theory and experiment for compressible rubberlike solids," Proceedings of the Royal Society of London. A. Mathematical and Physical Sciences, vol. 328 , no. 1575 , pp. 567-583, 1972.

[54] O. H. Yeoh, "Some forms of the strain energy function for rubber," Rubber Chemistry and Technology, vol. 66, pp. 754771, Nov. 1993.

[55] A. N. Gent, "A new constitutive relation for rubber," Rubber Chemistry and Technology, vol. 69, no. 1, pp. 59-61, 1996.

[56] C. O. Horgan and G. Saccomandi, "A description of arterial wall mechanics using limiting chain extensibility constitutive models," Biomechanics and Modeling in Mechanobiology, vol. 1, pp. 251-266, Apr. 2003.

[57] B. Rashid, M. Destrade, and M. D. Gilchrist, "Mechanical characterization of brain tissue in simple shear at dynamic strain rates," Journal of the Mechanical Behavior of Biomedical Materials, vol. 28, pp. 71 - 85, 2013.

[58] B. Rashid, M. Destrade, and M. D. Gilchrist, "Mechanical characterization of brain tissue in tension at dynamic strain rates," Journal of the Mechanical Behavior of Biomedical Materials, vol. 33, pp. 43 - 54, 2014. Forensic Biomechanics.

[59] L. R. G. Treloar, The physics of rubber elasticity. Oxford University Press, USA, 1975.

[60] J. E. Bischoff, E. M. Arruda, and K. Grosh, "Finite element modeling of human skin using an isotropic, nonlinear elastic constitutive model," Journal of Biomechanics, vol. 33, no. 6, pp. 645 - 652, 2000.

[61] J. E. Bischoff, E. M. Arruda, and K. Grosh, "Finite element simulations of orthotropic hyperelasticity," Finite Elements in Analysis and Design, vol. 38, no. 10, pp. 983 - 998, 2002.

[62] E. Jacquet, S. Joly, J. Chambert, K. Rekik, and P. Sandoz, "Ultra-light extensometer for the assessment of the mechanical properties of the human skin in vivo," Skin Research and Technology, vol. 23, 032017.

[63] J. Chambert, T. Lihoreau, S. Joly, B. Chatelain, P. Sandoz, P. Humbert, E. Jacquet, and G. Rolin, "Multimodal investigation of a keloid scar by combining mechanical tests in vivo with diverse imaging techniques," Journal of the Mechanical Behavior of Biomedical Materials, vol. 99, pp. 206-215, 072019.

[64] R. Ogawa and D. P. Orgill, "Mechanobiology of cutaneous wound healing and scarring," in Bioengineering Research of Chronic Wounds: A Multidisciplinary Study Approach (A. Gefen, ed.), pp. 31-42, Berlin, Heidelberg: Springer Berlin Heidelberg, 2009.

[65] J. Chambert, L. Zhao, D. Remache, and E. Jacquet, "Numerical analysis of keloid scar in the presternal area," Computer Methods in Biomechanics and Biomedical Engineering, vol. 15, no. sup1, pp. 23-24, 2012.

[66] R. Ogawa, "Keloid and hypertrophic scarring may result from a mechanoreceptor or mechanosensitive nociceptor disorder," Medical hypotheses, vol. 71, pp. 493-500, 082008.

[67] S. Akaishi, M. Akimoto, R. Ogawa, and H. Hyakusoku, "The relationship between keloid growth pattern and stretching tension: Visual analysis using the finite element method," Annals of Plastic Surgery, vol. 60, 2008.

[68] E. S. Pozos, The effect of skin tension on the formation of keloid scars. PhD thesis, School of Meterials, The University of Manchester, Manchester, UK, 2014.

[69] A. Logg, K.-A. Mardal, and G. N. Wells, eds., Automated Solution of Differential Equations by the Finite Element Method. Springer, 2012.

[70] H. Schmidt, T. Alber, T. Wehner, R. Blakytny, and H.-J. Wilke, "Discretization error when using finite element models: Analysis and evaluation of an underestimated problem," Journal of Biomechanics, vol. 42, no. 12, pp. 1926 - 1934 , 2009. 
[71] M. R. Molteno and T. H. Becker, "Mode I-III Decomposition of the J-integral from DIC Displacement Data," Strain, vol. 51, no. 6, pp. 492-503, 2015.

[72] H.-P. Chen and Y. Ni, "Finite element model updating," in Structural Health Monitoring of Large Civil Engineering Structures, pp. 123-154, 032018.

[73] J. Martins, A. Andrade-Campos, and S. Thuillier, "Comparison of inverse identification strategies for constitutive mechanical models using full-field measurements," International Journal of Mechanical Sciences, vol. 145, pp. 330 345, 2018.

[74] P. E. Farrell, D. A. Ham, S. W. Funke, and M. E. Rognes, "Automated derivation of the adjoint of high-level transient finite element programs," SIAM Journal on Scientific Computing, vol. 35, no. 4, 2013.

[75] P. Hauseux, J. S. Hale, S. Cotin, and S. P. A. Bordas, "Solving the stochastic hyperelasticity equation with a sensitivity derivative-driven Monte Carlo method," 4 2017. DOI: 10.6084/m9.figshare.4900298.v1.

[76] L. Bruno, F. Furgiuele, L. Pagnotta, and A. Poggialini, "A full-field approach for the elastic characterization of anisotropic materials," Optics and Lasers in Engineering, vol. 37, no. 4, pp. 417 - 431, 2002.

[77] J. Kajberg and G. Lindkvist, "Characterisation of materials subjected to large strains by inverse modelling based on in-plane displacement fields," International Journal of Solids and Structures, vol. 41, no. 13, pp. 3439 - 3459, 2004.

[78] J. N. Reddy, An introduction to continuum mechanics. Cambridge university press, 2007.

[79] C. O. Horgan, "The remarkable gent constitutive model for hyperelastic materials," International Journal of Non-Linear Mechanics, vol. 68, pp. 9 - 16, 2015. Mechanics of Rubber - in Memory of Alan Gent.

[80] B. Li, L. Liu, and Z. Suo, "Extension limit, polarization saturation, and snap-through instability of dielectric elastomers," International Journal of Smart and Nano Materials, vol. 2, no. 2, pp. 59-67, 2011.

[81] G. A. Holzapfel, Nonlinear Solid Mechanics: A Continuum Approach for Engineering. Chichester, UK: John Willey \& Sons, 2000.

[82] D. P. Bertsekas, "Multiplier methods: A survey," Automatica, vol. 12, no. 2, pp. 133 - 145, 1976.

[83] B. Beavis and I. M. Dobbs, Static Optimization. New York: Cambridge University Press, 1990.

[84] N. Harb, Identification inverse de paramètres biomécaniques en hyperélasticité anisotrope. $\mathrm{PhD}$ thesis, Université de Technologie de Belfort-Montbeliard, Bourgogne-Franche-Comté, France, 2013.

[85] S. P. A. Bordas, M. Duflot, and P. Le, "A simple error estimator for extended finite elements," Communications in Numerical Methods in Engineering, vol. 24, no. 11, pp. 961-971, 2008.

[86] J. P. Kaipio and E. Somersalo, Statistical and Computational Inverse Problems. New York: Springer Science Business Media, 2005.

[87] F. Daghia, S. de Miranda, F. Ubertini, and E. Viola, "Estimation of elastic constants of thick laminated plates within a bayesian framework," Composite Structures, vol. 80, no. 3, pp. 461-473, 2007.

[88] Y. Wang, Uncertainty Quantification of Digital Image Correlation and the Impact on Material Identification. PhD thesis, Katholieke Universiteit Leuven, Leuven, Belgium, 2015.

[89] C. Soo-Won and K.-J. Bathe, "On automatic mesh construction and mesh refinement in finite element analysis," Computers Structures, vol. 32, no. 3, pp. $911-936,1989$. 


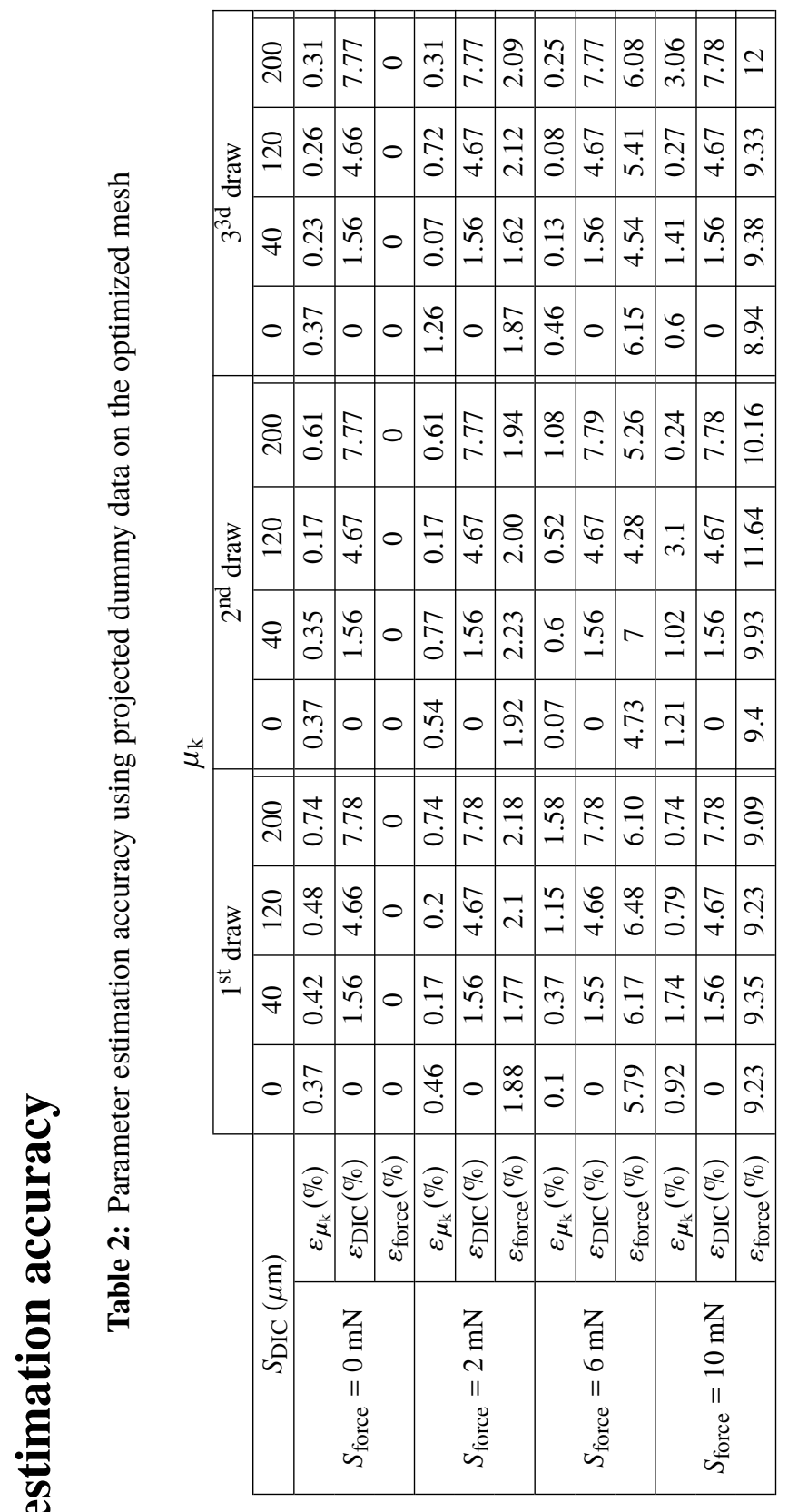

\begin{tabular}{|c|c|c|c|c|c|c|c|c|c|c|c|c|}
\hline \multirow{4}{*}{ 䲩 } & 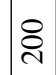 & 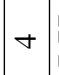 & $\stackrel{i}{r}$. & 0 & 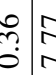 & $=\underset{\mathrm{i}}{\stackrel{\mathrm{d}}{\mathrm{C}}}$ & & $\stackrel{\curvearrowright}{\curvearrowright}$ & 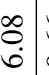 & \begin{tabular}{c}
$\stackrel{1}{0}$ \\
\hdashline \\
0
\end{tabular} & co & $\sim$ \\
\hline & 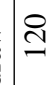 & $\overline{\mathrm{i}}$ & $\begin{array}{l}\stackrel{\bullet}{*} \\
\dot{+}\end{array}$ & 0 & $\stackrel{5}{8}$ & 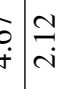 & : & $\begin{array}{l}\vec{b} \\
\dot{+}\end{array}$ & $\begin{array}{c}\overrightarrow{7} \\
\dot{m}\end{array}$ & $\begin{array}{l}b \\
0 \\
0\end{array}$ & & 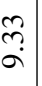 \\
\hline & of & $\begin{array}{l}\infty \\
0 \\
0\end{array}$ & :ִ & 0 & & 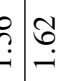 & d. & & $\stackrel{\vec{r}}{\stackrel{\leftrightarrow}{*}}$ & 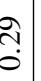 & & $\begin{array}{c}\infty \\
\cdots \\
\vdots \\
\vdots\end{array}$ \\
\hline & 0 & $\underset{\stackrel{f}{0}}{\stackrel{0}{0}}$ & 0 & 0 & & $b \mid$ & Ĩ. & 0 & $\begin{array}{c}n \\
0 \\
0\end{array}$ & $\underset{\substack{f \\
0}}{0}$ & & $\begin{array}{c}+ \\
\infty \\
\infty\end{array}$ \\
\hline \multirow{4}{*}{$\begin{array}{l}\text { 胥 } \\
\text { 严 } \\
\text { ते }\end{array}$} & \&્ণ & $\begin{array}{l}\infty \\
0 \\
0\end{array}$ & 尽 & 0 & $m: n$ & $=89$ & 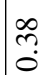 & $\frac{2}{i}$ & స్ & $\stackrel{f}{\circ}$. & & \begin{tabular}{l}
0 \\
\hdashline \\
0 \\
0
\end{tabular} \\
\hline & $\stackrel{\beth}{ }$ & 華 & $\begin{array}{l}\hat{0} \\
\dot{+}\end{array}$ & 0 & 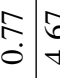 & $\begin{array}{l}0 \\
\dot{f} \\
\dot{i}\end{array}$ & 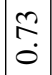 & $\begin{array}{l}\hat{\sigma} \\
\dot{\gamma}\end{array}$ & 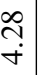 & $\stackrel{f}{\stackrel{f}{0}}$ & & | \\
\hline & q & $\begin{array}{l}0 \\
0 \\
0\end{array}$ & ?ִ. & 0 & 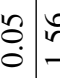 & 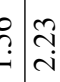 & 莗 & ?ִ & - & $\begin{array}{l}\text { tot } \\
\stackrel{0}{0}\end{array}$ & 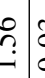 & $\tilde{\Omega}$ \\
\hline & 0 & 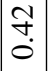 & 0 & 0 & \begin{tabular}{c}
\multirow{2}{*}{} \\
0
\end{tabular} & $0 \Omega$ & f̊. & 0 & 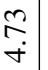 & 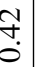 & & $\stackrel{+}{a}$ \\
\hline \multirow{4}{*}{ 鴍 } & $\underset{\sim}{\stackrel{1}{ }}$ & $\begin{array}{l}n \\
\hat{o}\end{array}$ & $\begin{array}{c}\infty \\
\substack{n\\
}\end{array}$ & 0 & $m: \frac{\infty}{2}:$ & 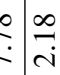 & $\vec{m}$ & $\begin{array}{l}\infty \\
\stackrel{2}{n} \\
\end{array}$ & $\frac{0}{6}$ & $\begin{array}{l}\hat{2} \\
\\
0\end{array}$ & $\stackrel{\infty}{*}$ & $\begin{array}{l}0 \\
\stackrel{0}{a} \\
a\end{array}$ \\
\hline & $\stackrel{\beth}{ }$ & $\begin{array}{l}0 \\
0 \\
0\end{array}$ & 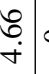 & 0 & $\stackrel{0}{0}:$ & $\begin{array}{lll}\dot{j} \\
\dot{j}\end{array}$ & F. & $\begin{array}{l}8 \\
\dot{+}\end{array}$ & 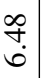 & $\stackrel{\vec{n}}{\longrightarrow}$ & & $\begin{array}{c}\stackrel{2}{a} \\
\sigma\end{array}$ \\
\hline & q & $\begin{array}{c}\text { ô. } \\
0 .\end{array}$ & 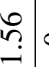 & 0 & \begin{tabular}{c}
$c$ \\
\hdashline \\
0
\end{tabular} & $\stackrel{2}{2}$ & $\begin{array}{c}n \\
\tilde{c} \\
0\end{array}$ & $n$ & $\frac{7}{6}$ & & : & 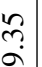 \\
\hline & 0 & 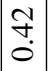 & 0 & 0 & 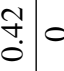 & $b \mid \begin{array}{l}\infty \\
\infty \\
\end{array}$ & $\stackrel{\text { I }}{0}$ & 0 & $\begin{array}{c}\stackrel{2}{n} \\
i\end{array}$ & 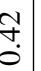 & & 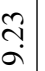 \\
\hline & & 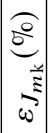 & c) & 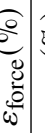 & b) & 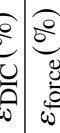 & 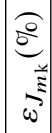 & 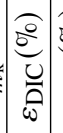 & $\begin{array}{c}0 \\
0 \\
0 \\
0 \\
0 \\
w \\
w\end{array}$ & 总 & $\begin{array}{l}0 \\
0 \\
0 \\
0 \\
0\end{array}$ & 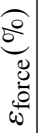 \\
\hline & $\stackrel{0}{0}$ & & 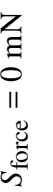 & & & 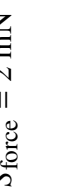 & & 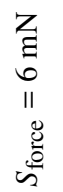 & & & & \\
\hline
\end{tabular}




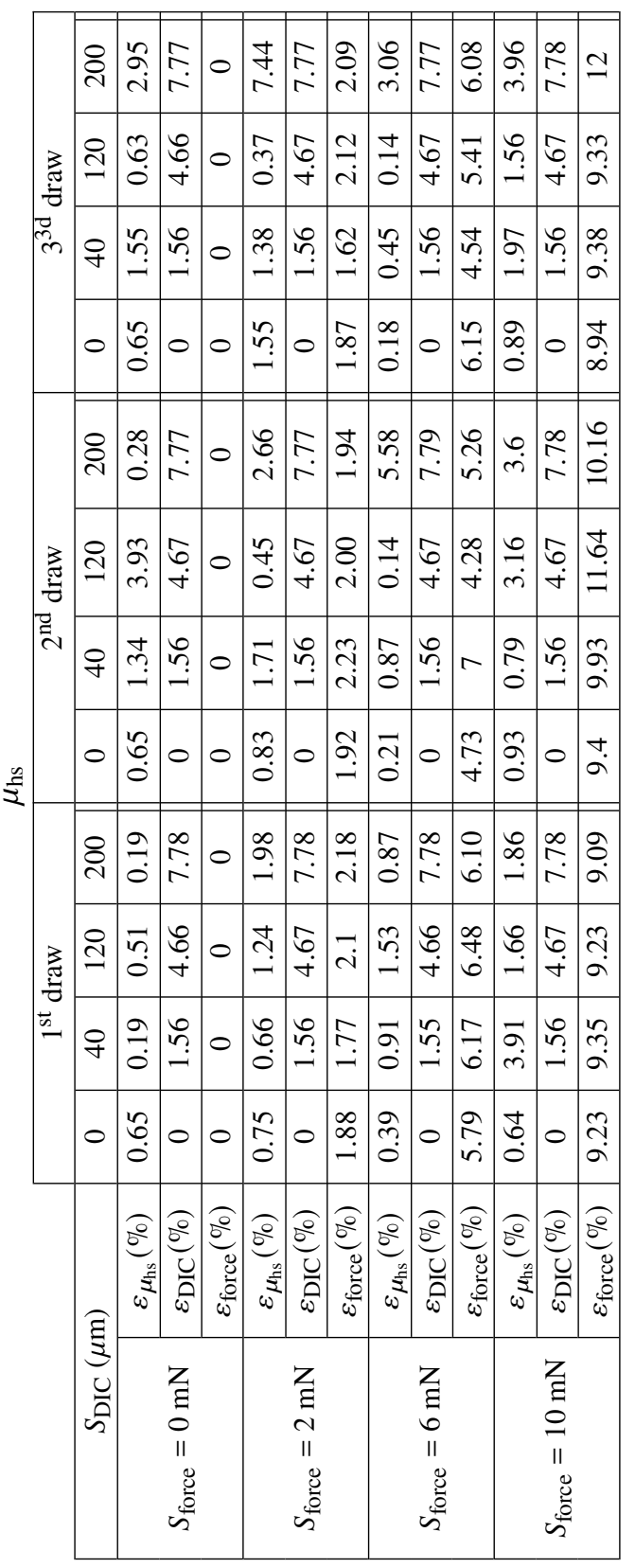

\begin{tabular}{|c|c|c|c|c|c|c|c|c|c|c|c|c|}
\hline \multirow{4}{*}{ 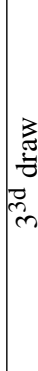 } & $\underset{i}{8}$ & ?ֶ. & $\stackrel{\overbrace{}}{\stackrel{2}{r}}$ & 0 & $\stackrel{?}{=}$ & 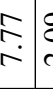 & 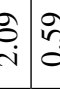 & 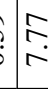 & {$\left[\begin{array}{l}\infty \\
0 \\
0\end{array}\right.$} & $\stackrel{\overbrace{}}{\stackrel{f}{*}}$ & & $\simeq$ \\
\hline & 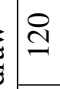 & $\begin{array}{l}0 \\
i \\
i\end{array}$ & $\begin{array}{l}\mathscr{0} \\
+ \\
+\end{array}$ & 0 & $\begin{array}{c}\hat{\sigma} \\
- \\
-\end{array}$ & $\begin{array}{l}\hat{b} \\
\dot{+} \\
\tau\end{array}$ & $\begin{array}{c}c \\
i\end{array}$ & $\hat{\vec{t}}$ & $\begin{array}{l}F \\
\text { in }\end{array}$ & f̊. & & $\overbrace{\sigma}^{m}$ \\
\hline & q & $\underset{-}{\stackrel{f}{*}}$ & 苂 & 0 & $\begin{array}{l}\vec{b} \\
i\end{array}$ & 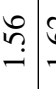 & 6 & 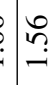 & 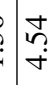 & $\stackrel{\bullet}{:}$ & & 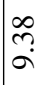 \\
\hline & 0 & $\stackrel{\text { ț }}{\rightarrow}$ & 0 & 0 & 苔 & 0 & $\begin{array}{c}\infty \\
-\infty \\
-\end{array}$ & 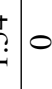 & $\frac{n}{6}$ & $\stackrel{\text { in }}{\rightarrow}$ & 0 & $\begin{array}{l}t \\
0 \\
\infty\end{array}$ \\
\hline \multirow{4}{*}{$\begin{array}{l}\text { 胥 } \\
\text { 晋 } \\
\text { ते }\end{array}$} & ¿্ণ & $\stackrel{n}{\stackrel{2}{g}}$ & 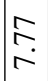 & 0 & $\begin{array}{l}\infty \\
n \\
0\end{array}$ & 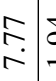 & $\vec{d}$ & 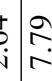 & 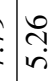 & & $\mid \begin{array}{l}\infty \\
2 \\
\end{array}$ & $\frac{0}{0}$ \\
\hline & & $\stackrel{\infty}{\infty} \underset{-}{-}$ & $\begin{array}{l}\hat{b} \\
\dot{+}\end{array}$ & 0 & $\stackrel{f}{f}$ & $\begin{array}{l}\hat{\sigma} \\
\dot{+}\end{array}$ & 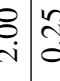 & $\begin{array}{l}\tilde{b} \\
+\end{array}$ & 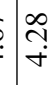 & त̂ & & $\begin{array}{l}\text { ț } \\
\stackrel{\text { J }}{\Xi}\end{array}$ \\
\hline & q & $\stackrel{\text { I }}{\rightarrow}$ & ?ִ & 0 & $\stackrel{\tilde{n}}{\longrightarrow}$ & 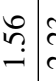 & \begin{tabular}{c|c}
$\mathcal{N}$ \\
\end{tabular} & \begin{tabular}{l}
3 \\
\hdashline
\end{tabular} & $r$ & $\stackrel{\leftrightarrow}{\longrightarrow}$ & ?ִ & $\hat{\sigma}$ \\
\hline & 0 & 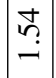 & 0 & 0 & $\stackrel{t}{\leftrightarrow}$ & & $\sigma=$ & 0 & $\stackrel{\overbrace{}}{\stackrel{\overbrace{}}{+}}$ & 空 & & $\stackrel{\nabla}{\circ}$ \\
\hline \multirow{4}{*}{ 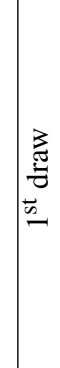 } & 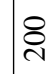 & 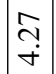 & 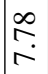 & 0 & $\begin{array}{l}\infty \\
\infty \\
i \\
\end{array}$ & 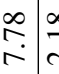 & \begin{tabular}{c|c}
$\infty$ \\
in
\end{tabular} & $\stackrel{n}{i}$ & $\begin{array}{l}0 \\
\vdots \\
0\end{array}$ & $\begin{array}{l}\infty \\
0 \\
0\end{array}$ & $\begin{array}{l}\infty \\
\stackrel{2}{r} \\
\end{array}$ & $\stackrel{\partial}{a}$ \\
\hline & & $\stackrel{m}{i}$ & $\begin{array}{l}\stackrel{\circ}{\circ} \\
+\end{array}$ & 0 & $\stackrel{0}{-}$ & \begin{tabular}{l|l}
$\vec{\sigma}$ \\
$\dot{f}$
\end{tabular} & $\bar{i}$ & 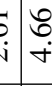 & $\begin{array}{l}\mathfrak{f}_{f} \\
\dot{f}\end{array}$ & $\begin{array}{l}a \\
\text { i }\end{array}$ & & તૈ. \\
\hline & q & 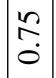 & חי & 0 & $\bar{m}$ & $\begin{array}{l}n \\
\\
\end{array}$ & $=$ & $\begin{array}{l}t \\
\dot{x}\end{array}$ & $?$ & $\underset{-}{\stackrel{\infty}{\infty}}$ & & $\begin{array}{l}m \\
m \\
a\end{array}$ \\
\hline & 0 & 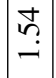 & 0 & 0 & 总 & $\left.0\right|^{\alpha}$ & $\infty$ & $\stackrel{0}{0}$ & $b \mid \begin{array}{l}\hat{\imath} \\
i n\end{array}$ & 帘 & & \\
\hline & 递 & 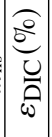 & 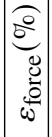 & 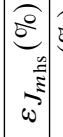 & 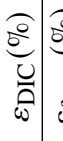 & $\begin{array}{c}0 \\
0 \\
0 \\
0 \\
\omega \\
\omega\end{array}$ & 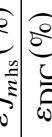 & 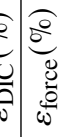 & 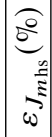 & 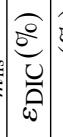 & \\
\hline & & & $\begin{array}{l}Z \\
\text { g } \\
\text { O } \\
\text { II }\end{array}$ & & & 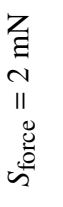 & & 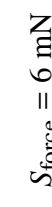 & & & 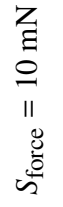 & \\
\hline
\end{tabular}




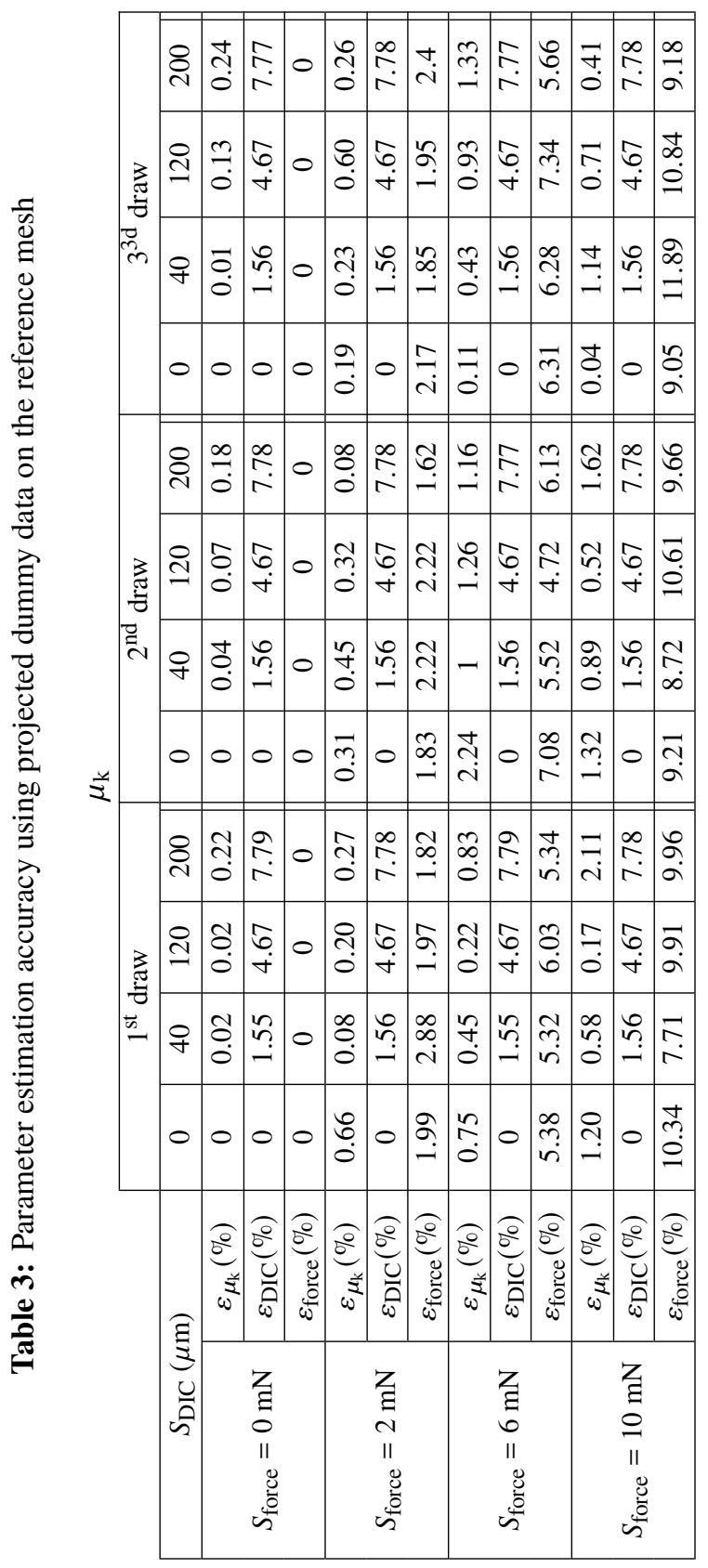

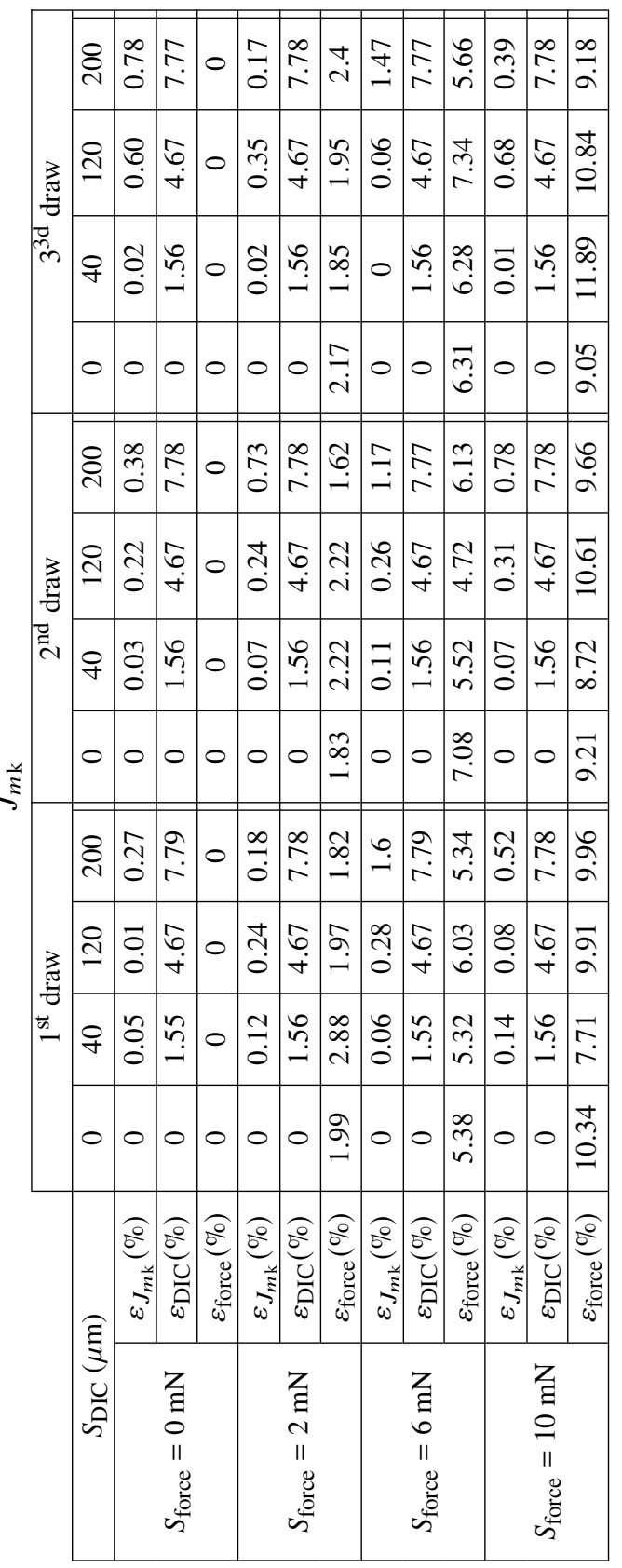




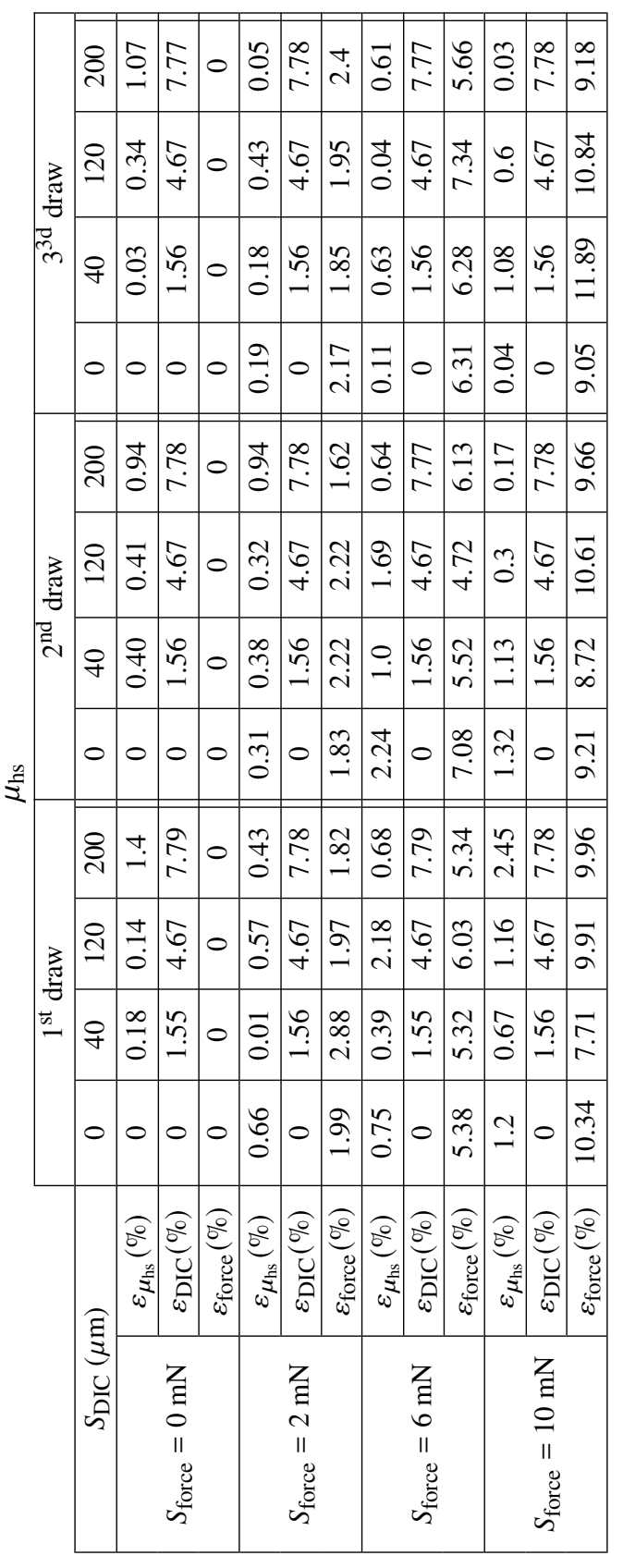

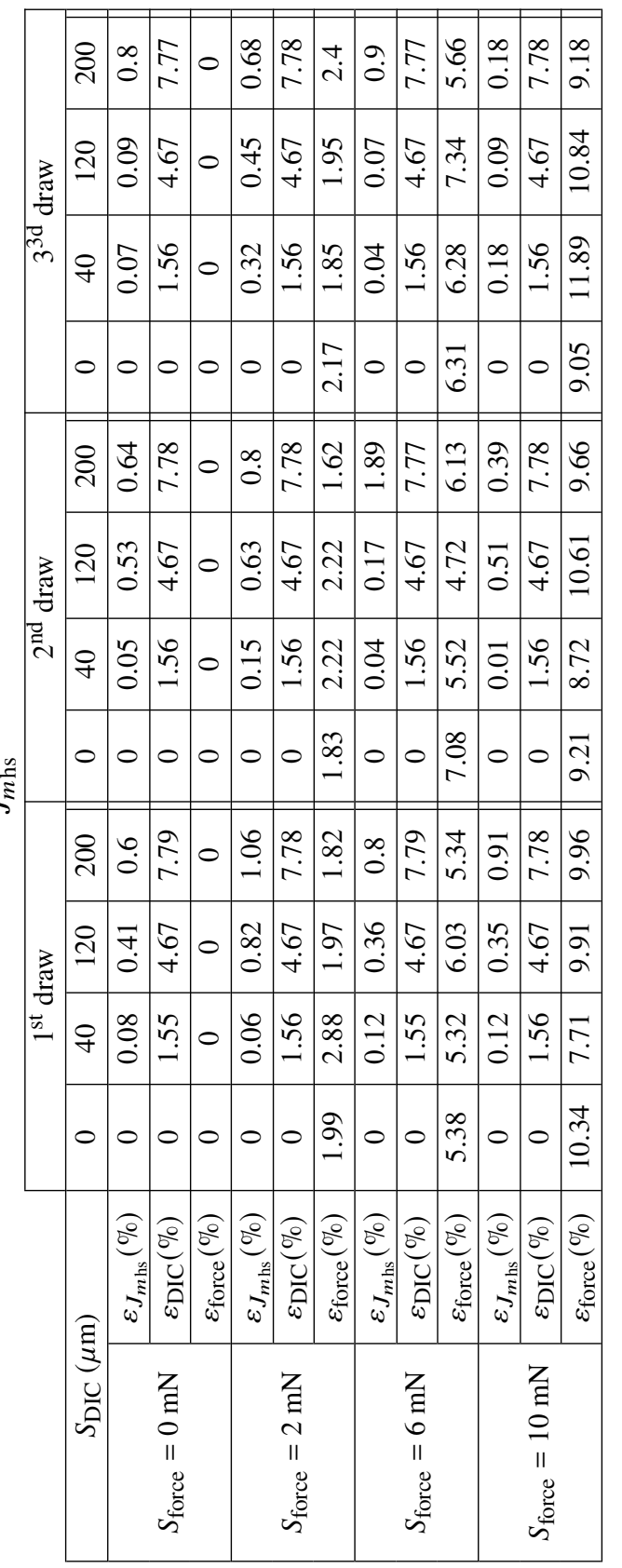




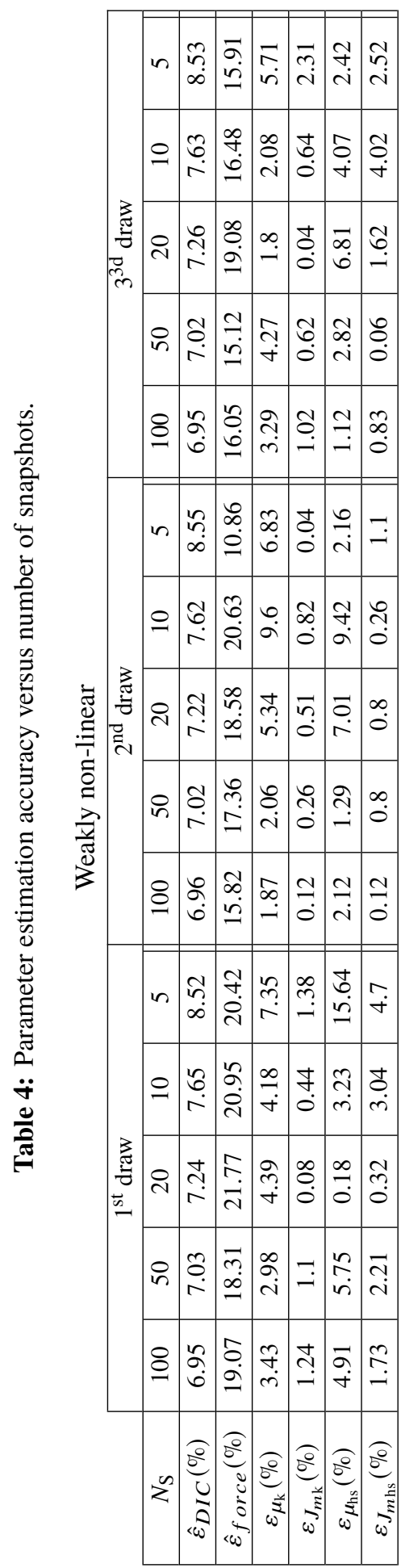

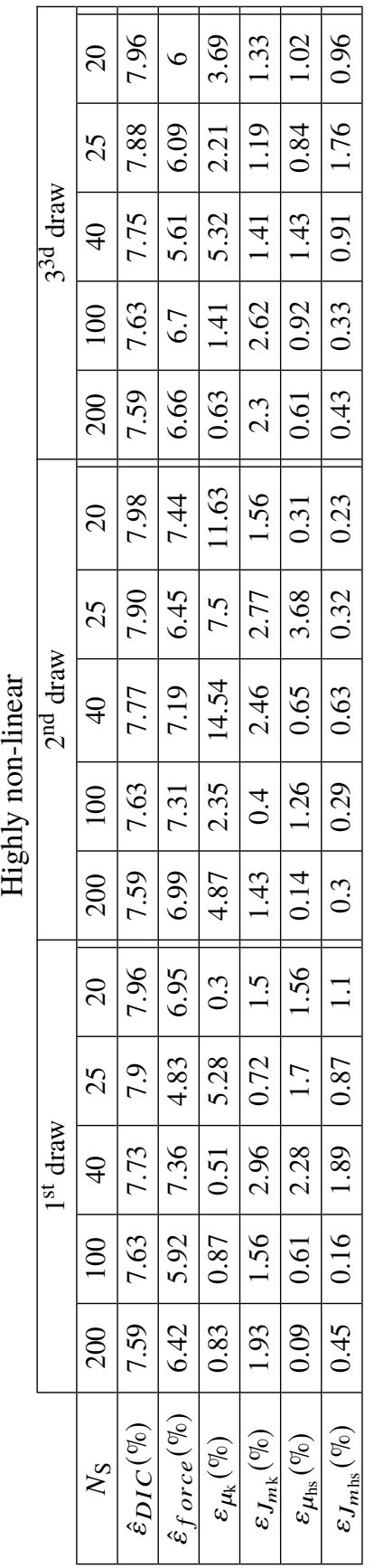




\section{B Inverse solutions}
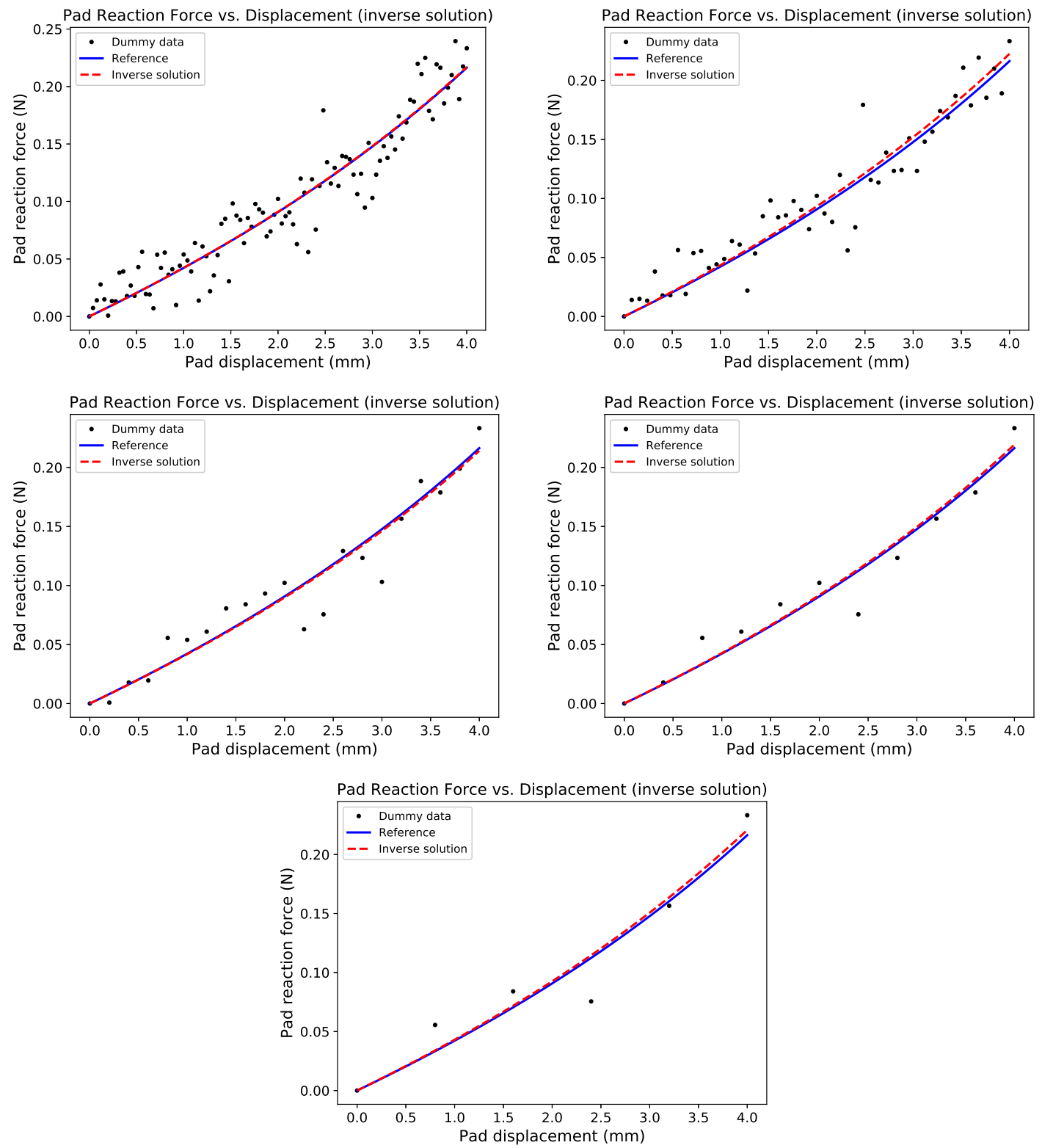

Figure 15: Parameter estimation accuracy performed on noisy dummy data for each observation pseudo-times set $N_{\mathrm{S}}=\{5,10,20,50,100\}$. The material parameters are chosen such that the response is weakly non-linear. The artificial data are projected on a 44k Lagrange-P1 elements-mesh (reference). 

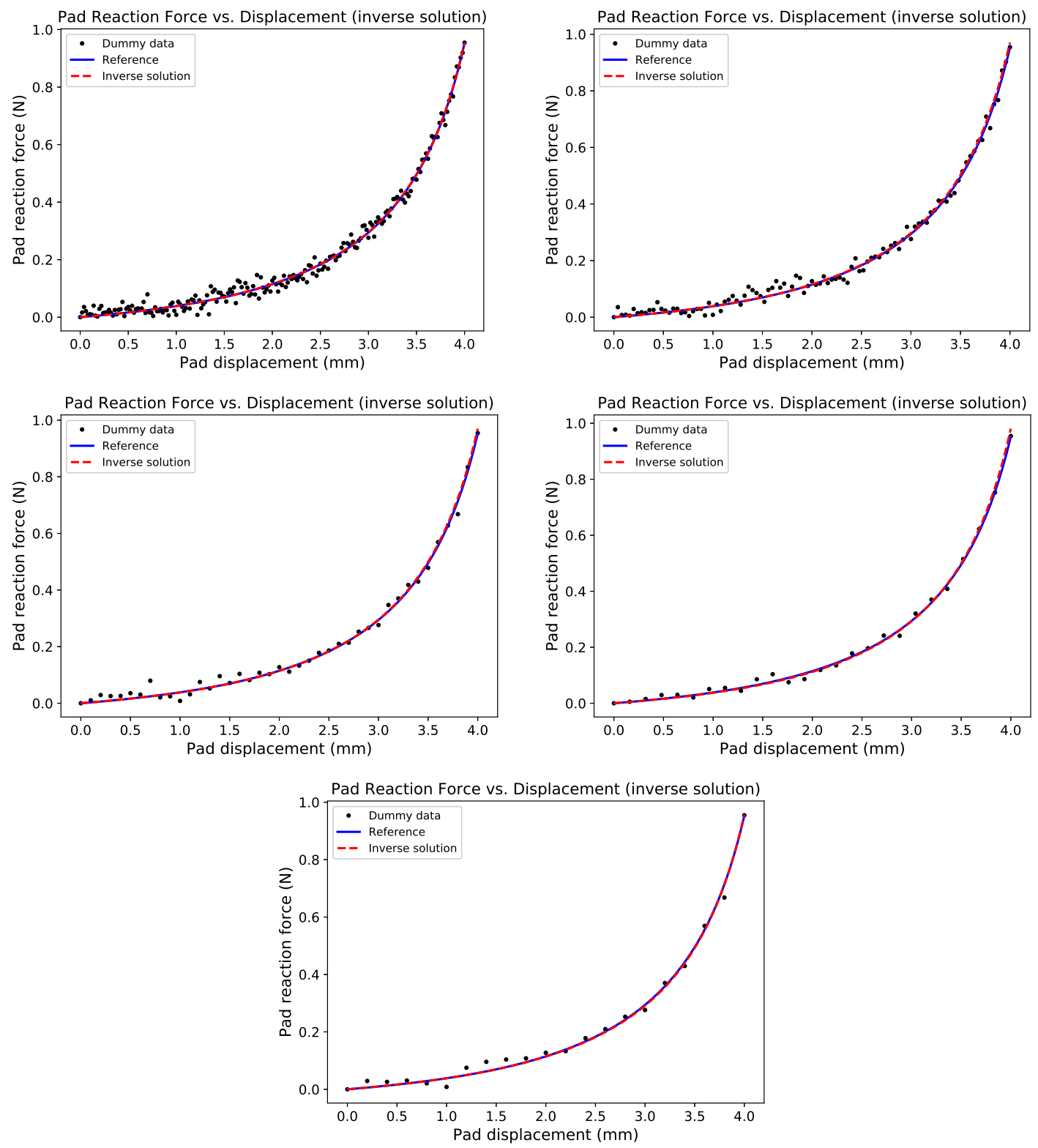

Figure 16: Parameter estimation accuracy performed on noisy dummy data for each observation pseudo-times set $N_{\mathrm{S}}=\{20,25,40,100,200\}$. The material parameters are chosen such that the response is highly non-linear. The artificial data are projected on a $44 \mathrm{k}$ Lagrange-P1 elements-mesh. 


\section{Observed costs}
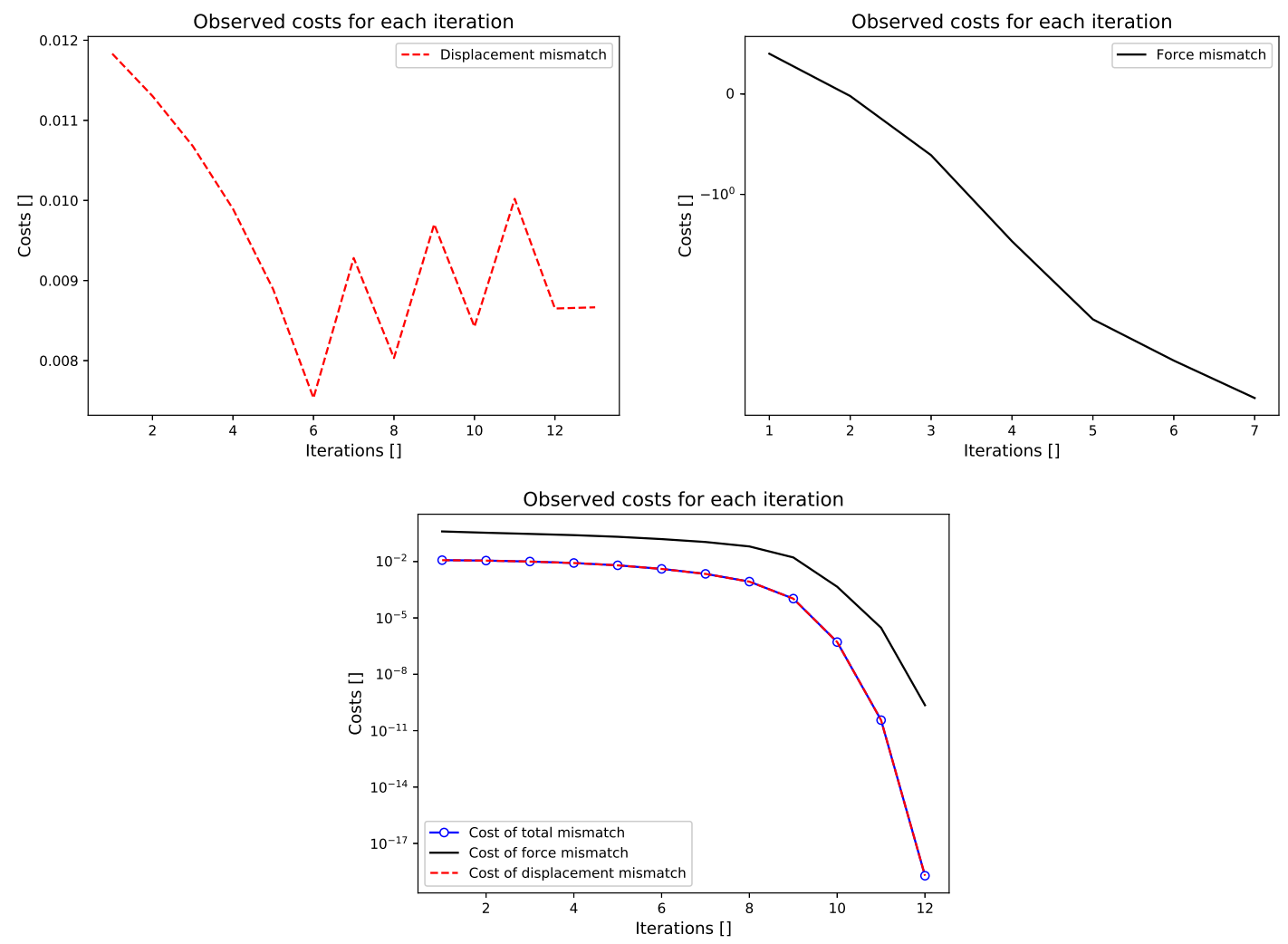

Figure 17: Observed costs of respective objective functions $\mathcal{J}_{\mathrm{u}}, \mathcal{J}_{\mathrm{f}}$ and $\mathcal{J}+\Lambda \mathcal{G}$ during inverse identification process. The computations have been stopped in two first cases because of divergence of forward non-linear FEM solver. 